\title{
Marble bowing: comparative studies of three different public building facades
}

\author{
S. Siegesmund $\cdot$ J. Ruedrich $\cdot$ A. Koch
}

Received: 23 January 2008/ Accepted: 25 March 2008/Published online: 16 April 2008

(C) The Author(s) 2008

\begin{abstract}
The veneer cladding of the Oeconomicum (OEC, Göttingen), the State Theatre of Darmstadt (STD, Darmstadt) and of the State and University Library (SUB, Göttingen) is characterised by pronounced bowing after a short time of exposure. Direct comparison of bowing data related to measurements from 2000 to 2003 at the SUB clearly show that the amplitude in bowing had significantly increased. The bowing is different in intensity and orientation (concave, convex). The cladding material (Peccia marble, Rosa Estremoz marble and Carrara marble) are different in lattice preferred orientation, grain size distribution and grain interlocking. Depending on the bowing, panels may show cracks mostly initiated at the dowels. The percentage of visible cracks and breakouts increases with the amplitude of bowing except for the STD. Repetitive heating-cooling under dry conditions leads to considerable inelastic residual strain only after the first or second thermal cycle. The residual strain continuously increases again if water is present, whereby the moisture content after a thermal cycle has a certain impact on the decay rate. The water-enhanced thermal dilatation strongly correlates with the deterioration rate obtained from the laboratory bow test. Detailed petrophysical investigations provide evidence that with increasing bowing a decrease of mechanical properties (flexural strength or breaking load at dowel hole) occur. Marble degradation is also connected with the increase in porosity and a general shift of the maximum
\end{abstract}

S. Siegesmund $(\bowtie) \cdot$ J. Ruedrich

GZG, Universität Göttingen, Goldschmidtstr.3,

37077 Göttingen, Germany

e-mail: ssieges@gwdg.de

A. Koch

RWTH Aachen University, Lochnerstr. 4-20,

52056 Aachen, Germany pore radii to larger pore sizes. On-site damage analyses were combined with laboratory tests of the bowing potential to constrain factors that may influence the risk failure. The experimental bowing data clearly demonstrate that after 40 heating cycles combined with the effect of moisture a certain impact on the decay rate is observed. In the case of demounted panels the bowing tests show that already strongly deformed panels from the building exhibit a lower bowing potential than those with lower amplitudes of bowing. This is not the general case for all marble types. Finally, the artificial bowing causes a significant reduction of the flexural strength and the breaking load at the dowel hole. The strength loss of the experimentally aged claddings combined with on-site damage analyses led to conclusions concerning risk assessment and the predicted lifetime of the investigated marble claddings.

Keywords Bowing - Marble - Building mapping · Residual strain $\cdot$ Thermal expansion $\cdot$ Bowing potential

\section{Introduction}

Numerous cases of damage on sculptures, gravestones, architectural heritage or facade stones made from marble indicate that its deterioration when used as building stones depends mainly on climate (Fig. 1). Chemical mechanisms have received much attention in recent years with a special emphasis on the effects of acid rain or biofilms. It has been shown that the initial reaction of calcite surfaces to incident rainfall produces clear morphological alteration even within a short term of exposure (Grimm 1999). Recently, physical weathering is considered to be the initial stage of deterioration of marbles (e.g. Siegesmund et al. 2000, 2007). 
Fig. 1 Representative decay pattern of marbles; a weathered Prieborn marble column at the Marmorpalais Potsdam, b SEMphotomicrograph of a weathered Grosskunzendorf marble due to selective solution phenomena, c SEM-photomicrograph showing the biological action, i.e. fungal hyphae populating microcracks, open grain boundaries or cleavage planes of calcite. The organisms have penetrated several millimiters into the marble. The dissolution of calcite may be due to the biological action. $\mathbf{d}$ deformed facade cladding made of Carrara marble from the Finlandia Hall in Helsinki, e bent gravestone (Carrara marble) from the cemetery Montmartre in Paris, $\mathbf{f}$ microfabrics of a strongly deformed marble illustrating the progressive opening of grain boundaries and the development of intergranular microfractures (SEM image)
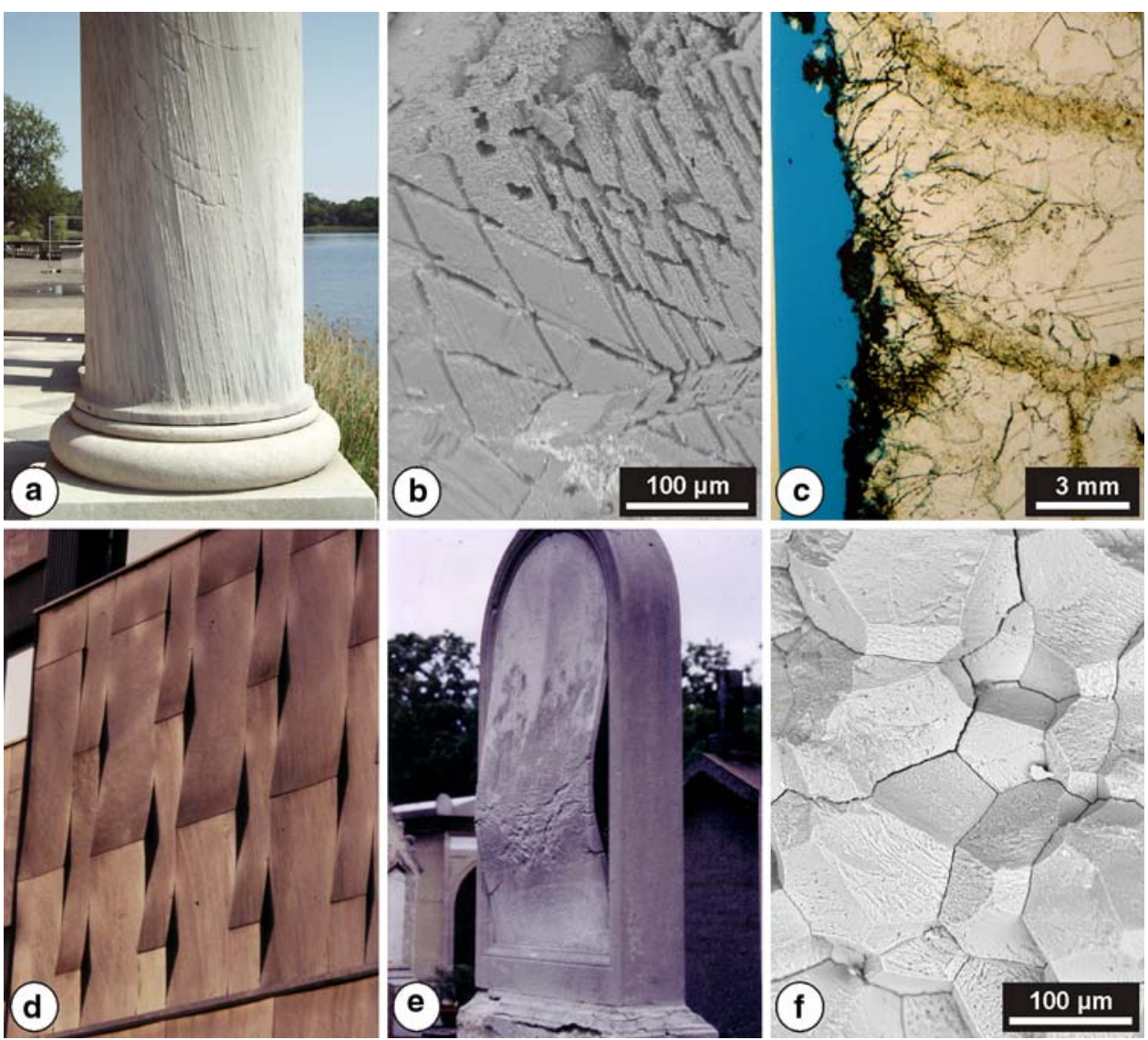

Durability is an important issue to consider when specifying stones as cladding material for exterior exposure. The use of stone panels as cladding materials for facade has undergone a considerable increase in the last decades. Durability problems of marble claddings focusing on the most spectacular deterioration feature known as the so-called bowing behaviour. The complete replacement of facade panels of some prestigious buildings like the Amoco building in Chicago (Logan et al. 1993), the Finlandia Hall in Helsinki or the Grand Arche de la Defense in Paris all made of some varieties of marble coming from the Carrara area are often cited examples for the existing concerns on the durability of these materials. However, bowing is already frequently reported from ancient gravestones (e.g. Grimm 1999) and also for those of up to 8 or $9 \mathrm{~cm}$ in thickness showing this behaviour. Detailed knowledge of the mechanisms and rates of decay is essential in protecting historic stone monuments: in the case of marble panels economic quantity is important. The replacement of all 43,000 marble panels of the Amoco building with granite required US $\$ 65$ million (Cohen and Monteiro 1991).

The reasons for the observed deformation are still under discussion. Kessler (1919) found that repeated heating may lead to permanent dilatation due to microfracturing. Rosenholtz and Smith (1949), Sage (1988) or Ondrasina et al.
(2002) reported length changes of $1 \mathrm{~mm} / \mathrm{m}$ due to heating and cooling. Thermally treated marbles which do not return to initial length changes after heating or cooling can show an inelastic residual strain even as a result of very small temperature changes (Battaglia et al. 1993). In a more systematic study, Siegesmund et al. (1999, 2000), Zeisig et al. (2002) or Ruedrich (2003) showed, that, depending on the length change behaviour under thermal treatment four distinct groups of marbles can be distinguished. Bortz et al. (1988) and Thomasen and Ewart (1984) concluded that a variation in moisture contents may be responsible for the deformation. Winkler (1996) favoured the role of moisture since continuous rows of ordered water molecules may cause swelling by elongation and stone disruption. Koch and Siegesmund $(2002,2004)$ had shown that the degree in bowing is controlled by the combined effect, i.e. temperature cycles under the presence of moisture (see also Grelk et al. 2004).

Logan et al. (1993) or Logan (2004) explained the bowing of marble slabs on the Amoco building as being due to the anomalous expansion-contraction behaviour of calcite combined with the release of locked residual stresses. This was also extensively discussed by Scheffzuek et al. $(2004,2007)$ by calculating the microstrain based on neutron diffraction data. 
To constrain the effect of bowing a detailed study on three different buildings (Oeconomicum and the State University Library building at Göttingen as well as the State Theatre of Darmstadt) was performed (Fig. 2). These buildings are cladded with different marble types: Oeconomicum (OEC): Peccia marble or Crystallino Virginio; State University Library building (SUB): Carrara marble or more specific the "Bianco Carrara Venato Gioia" and the State Theatre of Darmstadt (STD): Rosa Estremoz marble. At first the intensity of bowing of all panels was quantified in order to detect the influence of different panel sizes, building physics and exposition. The more recently obtained data were also compared with preliminary on-site data obtained in 2000 in the case of the SUB. Marble panels from the buildings with different bowing intensities were removed and characterised with respect to the mineralogy, rock fabrics and by rock technical properties (porosity, flexural strength, breaking load at dowel hole, etc.). In addition, an experimental approach to investigate the bowing potential of all removed panels was also performed in the laboratory by artificial weathering and compared with findings from the buildings.

\section{Investigated buildings and materials}

The Oeconomicum building (OEC) at the University of Goettingen (Fig. 2a) was built in 1966. The three-stored rectangular building has a length of $83 \mathrm{~m}$ in the northsouth direction and a width of $55 \mathrm{~m}$ in the east-west direction with a height of $13 \mathrm{~m}$. All facades are clad with panels of a white to dark, strongly decorated marble of identical dimensions (length $128 \mathrm{~cm}$, width $67 \mathrm{~cm}$ and thickness $3 \mathrm{~cm}$ ). Each elevation has four rows of panels with windows in between (height $180 \mathrm{~cm}$ ), each with a row of ventilation ducts (height $50 \mathrm{~cm}$ ) above. In total 1,556 marble panels were used as ornamentation on the building, corresponding to a total area of $1,300 \mathrm{~m}^{2}$. The slabs are mounted with a kerf on a continuous rail at the bottom and are held by a "ledge" at the top.

The cladding material at the Oeconomicum building is a coarse-grained Peccia marble ("Cristallino Virginio") from Switzerland. It consists mostly of a dark to white, sometimes light whitish calcitic matrix which is transacted by brownish biotite rich veins or greyish graphite veins. The veins appear in a millimetre to centimetre scale, sometimes in a decimetre scale or they may be completely absent. The veins define the foliation which is sometimes folded.

Microscopically the marble show a seriate interlobate fabric (Figs. 3, 4, 5, 6). Interlobate grains predominantly show curved, less often straight grain boundaries where subgrains and bulging often occur. More evidence of crystal-plastic deformation is presented by undulose extinction and frequent deformation twins which are sometimes bent. Accessory muscovite $(0.2-0.5 \mathrm{~mm}$ in size) and quartz (about $0.2 \mathrm{~mm}$ in size) appear between

Fig. 2 Representative views of the facades from the a Oeconomicum, b State Theatre Darmstadt (STD) and c State University Library building (SUB). Critical panels of the STD are replaced by panels made from brass, while those from the SUB were replaced by fibre cement panels

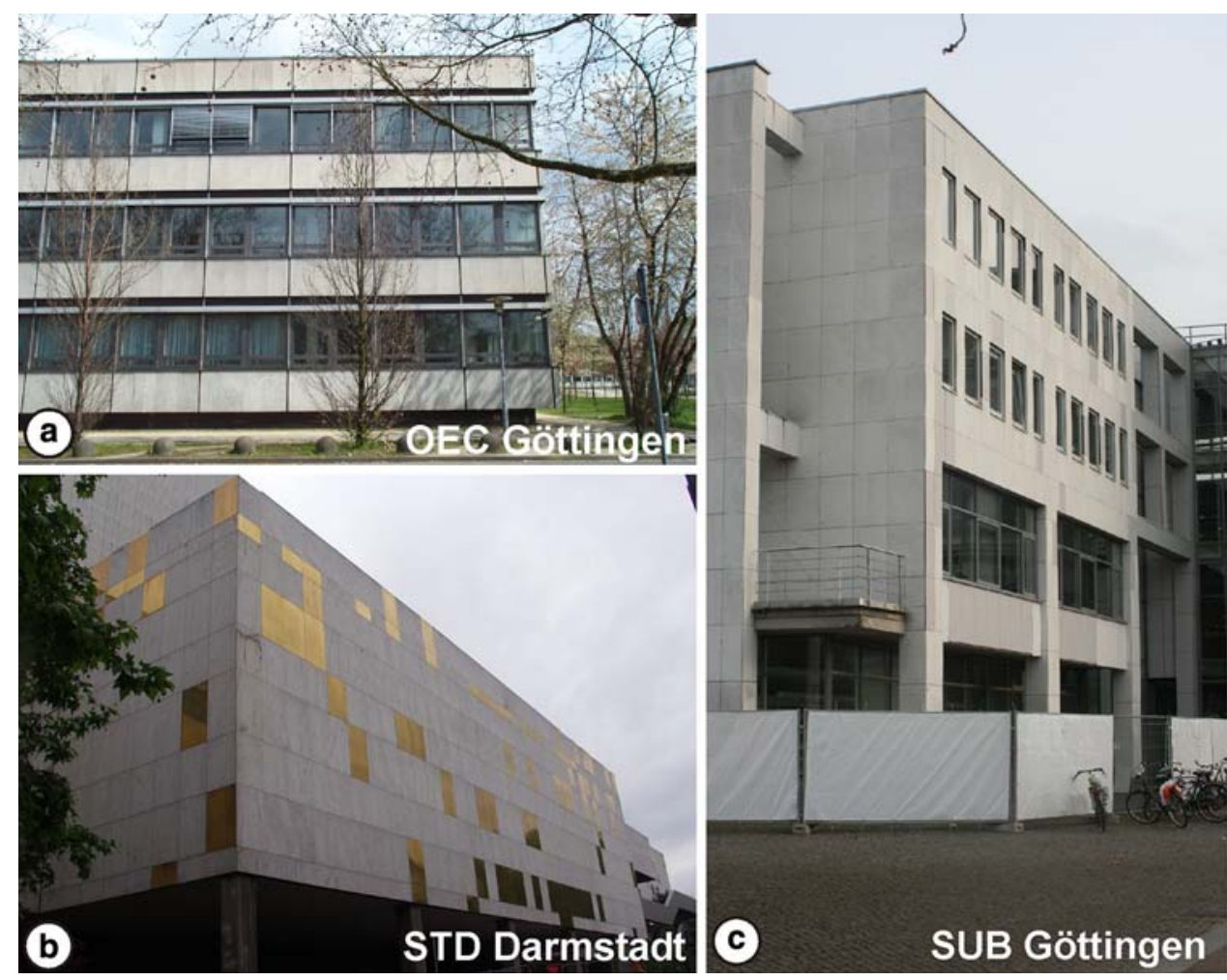


calcite grains or as calcite inclusions. Isolated elongated aggregates (up to $2 \mathrm{~mm}$ in size) are observable containing quartz and mica. The image analyses reveal the grains to have a moderate shape-preferred orientation parallel to the foliation (Fig. 5a). The calcite crystals show a grain size distribution ranging from 0.4 to $5.0 \mathrm{~mm}$ at an average of $1.5 \mathrm{~mm}$ (Fig. 6a). For the quantification of the lattice preferred orientation (texture) of calcite crystals neutron diffraction was applied. The measurements were carried out at the time-of-flight texture diffractometer at the pulsed reactor IBR-2 of the Frank Laboratory for Neutron Physics of the Joint Institute of Nuclear Research at Dubna, Russia (Siegesmund et al. 2000). The investigated sample of Peccia marble represents a $c$-axis fibre type with a weak tendency to form an intermediate fibre-type (cf. Leiss and Ullemeyer 1999). The texture (Fig. 7) is characterised by a single intensity maximum of the $c$-axes (006)-poles normal to the foliation, which is slightly elongated. With a maximum of 2.7 multiples of random distribution (mrd) the marble is relatively medium textured.

The State Theatre of Darmstadt (STD, Fig. 2b) was built in 1972. The eight-story building has a length of $180 \mathrm{~m}$ in the east-west direction and a width of $95 \mathrm{~m}$ in the northsouth direction. The facade is ventilated and thermally isolated. All facades are clad with panels of Rosa Estremoz marble. Different panel dimensions occur whereas the thickness is $3 \mathrm{~cm}$. The most frequent height is $160 \mathrm{~cm}$, the common width are $60-70 \mathrm{~cm}$. In total a number of about 2,200 marble panels were used as cladding on the building.

The cladding material at the theatre is a fine- to mediumgrained marble decorated by a network of greyish to brownish layers defining the foliation. The foliation is more or less vertical to the panel surfaces but oriented parallel to the panel long axes (Fig. 3b). Partly, 1-2 cm thick coarsegrained layers are also oriented parallel to the foliation. More rarely up to dm-thick layers of a pure calcite matrix can be observed. At many panels up to dm-long healed cracks of 1-10 mm in width with grey colour occur, which are generally oriented perpendicular to the foliation.

The investigated sample of the Rosa Estremoz marble is characterised by a mainly seriate and polygonal to interlobate grain fabric (Figs. 4b, c, 5b). The grain boundaries are mostly curved or irregular, rarely straight. The grain size distribution ranges from 0.1 to $1.5 \mathrm{~mm}$ with an average of about $0.2 \mathrm{~mm}$ (Fig. 6b). Undulose extinction as well as subgrain formation are rarely observed, which suggests static recrystallisation as the dominant mechanism of fabric formation. The shape preferred orientation defines a continuous foliation and is strongly parallel to the $\mathrm{Y}$ and the $\mathrm{X}$-direction (visible in XZ- and in XY-sections, Fig. 5b). The texture of the investigated marble sample also represents a c-fibre type. The slightly elongated $c$-axis maximum is oriented perpendicular to the foliation, the $a$-axis forms a great circle distribution subparallel to the foliation plane. The intensity of the texture, which is best represented by the relative $c$-axis maximum, is with $2.9 \mathrm{mrd}$ the highest of the investigated marbles in this work (Fig. 7).

The Lower Saxony State and University Library (SUB) in Göttingen (Fig. 2c) was built in 1991. The four-storied neo-classicism style building has a length of $150 \mathrm{~m}$ in the north-south-direction and a width of $60 \mathrm{~m}$ in the eastwest-direction with a height of $17 \mathrm{~m}$. All facades are clad with panels of white Carrara marble (Fig. 3c). Different panel dimensions occur. The thickness is $4 \mathrm{~cm}$ throughout the facade, except for a part of the roof levels where the largest sized panels of $151 \mathrm{~cm}$ height and $74 \mathrm{~cm}$ width have a thickness of $5 \mathrm{~cm}$. Otherwise the most frequent height is $104 \mathrm{~cm}$, the most common widths are 74 and $45 \mathrm{~cm}$. The panels are mostly fixed with two pairs of horizontal or vertical stainless steal dowels. In total 4,000 marble panels were used as cladding on the building, corresponding to a total of about $3000 \mathrm{~m}^{2}$. The widths of open joints between the panels was originally $8 \pm 2 \mathrm{~mm}$. The panel surface is honed. The cladding is
Fig. 3 Macroscopic fabrics of the marbles investigated: a Peccia, b Rosa Estremoz and c Carrara

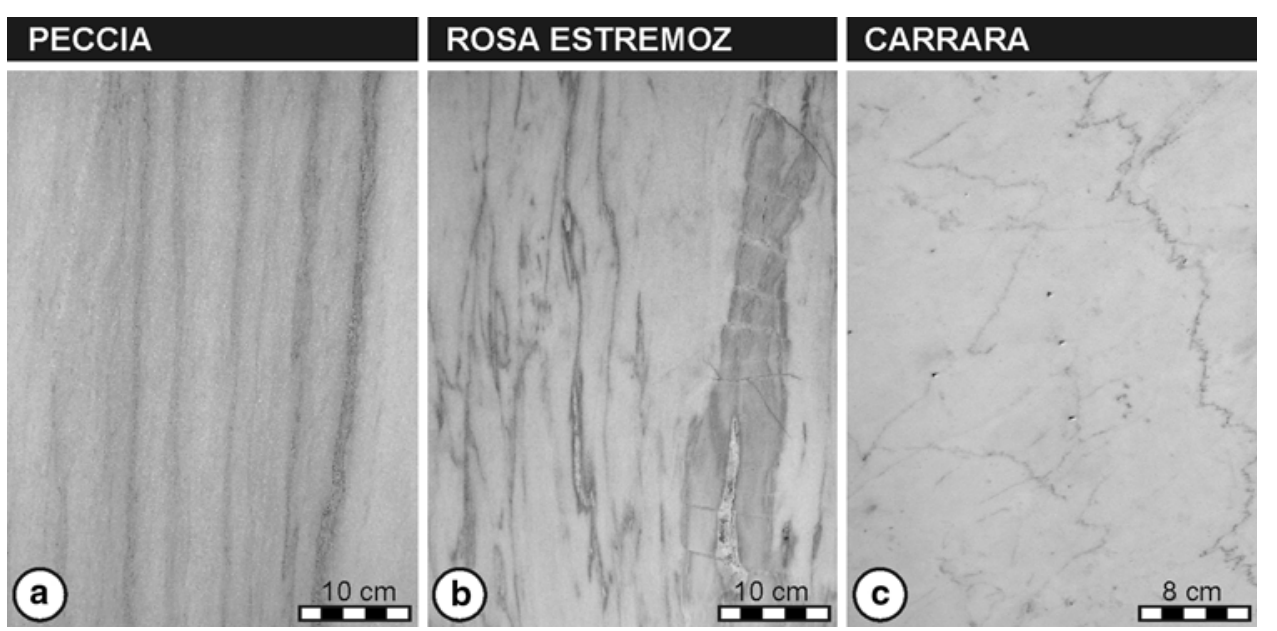


Fig. 4 Representative thin section images of the selected marbles illustrating the grain boundary configuration, grain size and the microstructure: $\mathbf{a}-\mathbf{b}$ Peccia, c-d Rosa Estremoz and e-f Carrara
Fig. 5 Grain boundary orientation of the marble from Peccia (a, d), Rosa Estremoz $(\mathbf{b}, \mathbf{e})$ and Carrara $(\mathbf{c}, \mathbf{f})$. To illustrate the preferred orientation of the grain boundaries line drawings in the three perpendicular cross sections are shown $(\mathbf{a}-\mathbf{c})$ while the statistical orientations of the grain boundaries are given in the XY-, XZ- and YZ-section frame $(\mathbf{d}-\mathbf{f})$

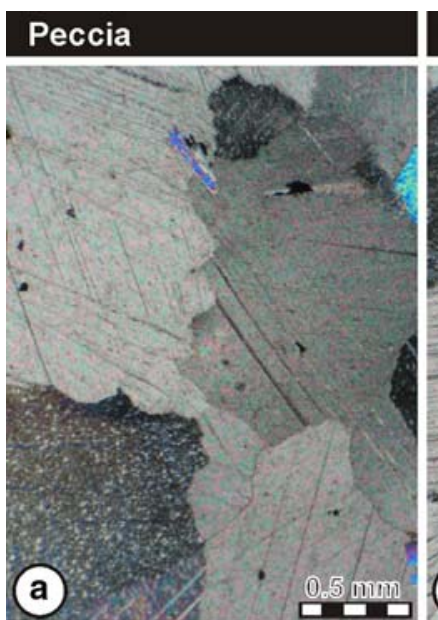

\section{Rosa Estremoz}
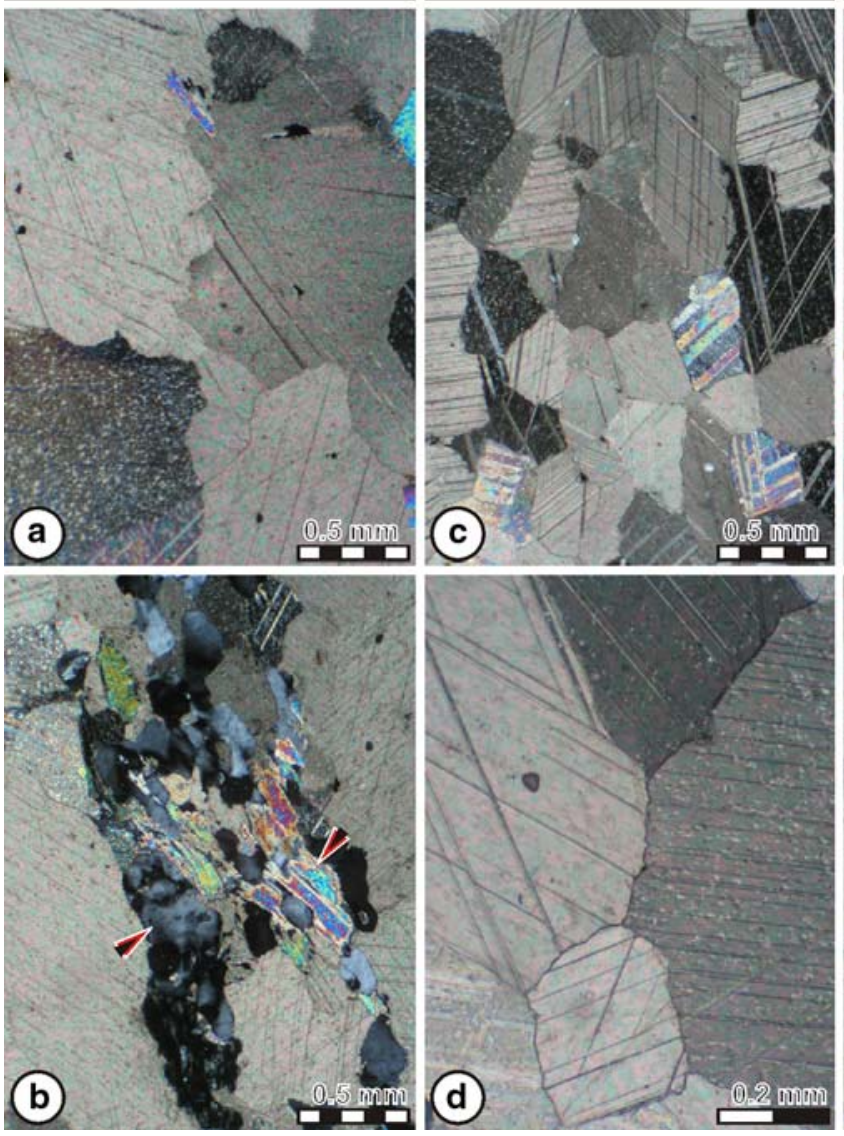

\section{Carrara}
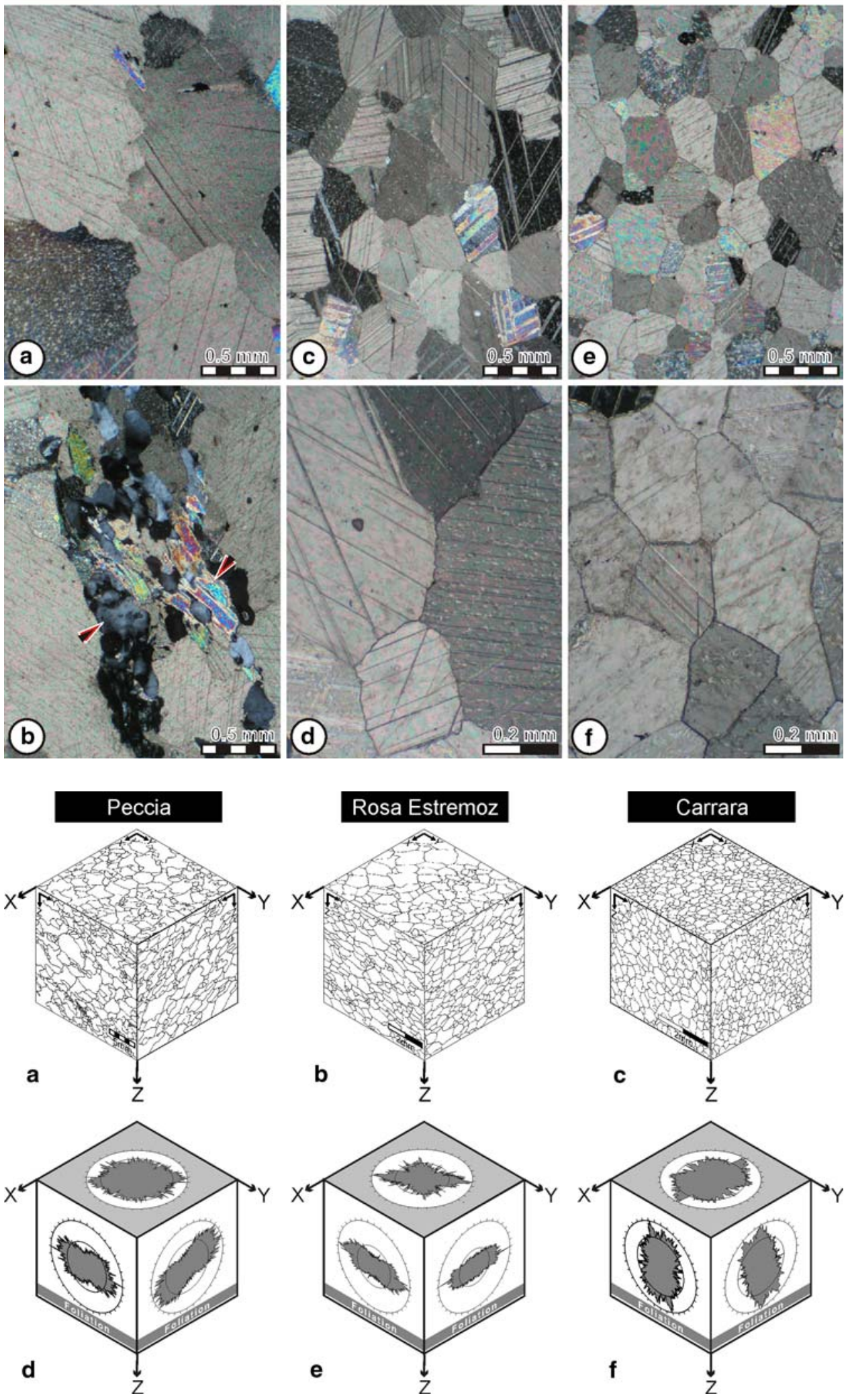

shaded during the afternoon. The same holds true to the right third of the west facade during the middle of the day. 
Fig. 6 Grain size distribution of the three investigated marbles

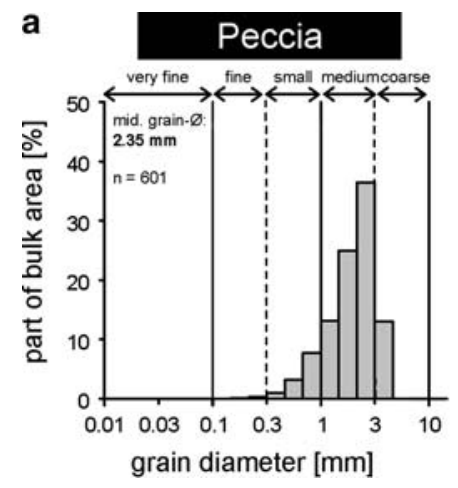

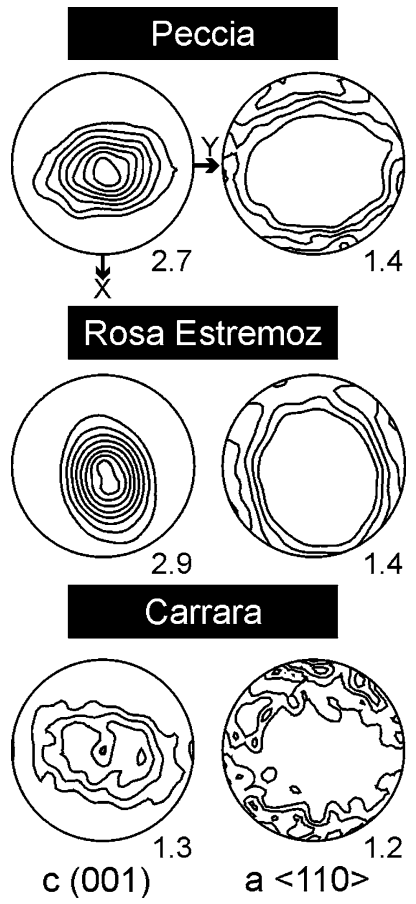

Fig. 7 Lattice preferred orientation of the different marble types for the $c$-axis and $a$-axis (lower hemisphere, stereographic projection, the relative maxima are given)

The matrix of the Carrara marble is light white, intersected by a network of grey mm-thick veins without any preferred orientation. Thus, no clearly developed foliation is observable. In thin sections the marble shows a nearly equigranular-polygonal (granoblastic) foam structure with straight grain boundaries and $120^{\circ}$ triple-point junctions (Fig. 4e, f). Only a very few grains are twinned. The macroscopically visible grey veins are finer grained, but show very strong unduluose extinction. The unduluose extinction and the formation of subgrains occur to such an extent, that the individual grains are difficult to detect. Grain boundaries are interlobating and there is a high amount of fluid inclusions or graphite which is probably the cause for the grey colour of the veins. The grain size has an average $0.3 \mathrm{~mm}$ and ranges closely between 0.1 and

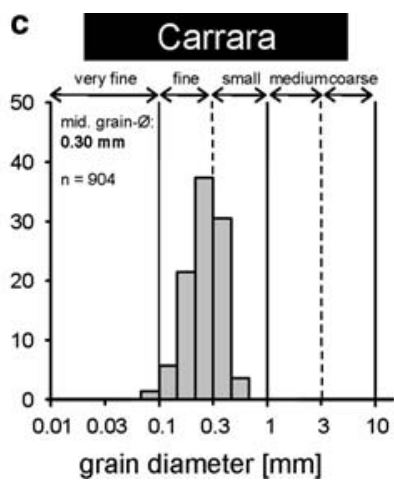

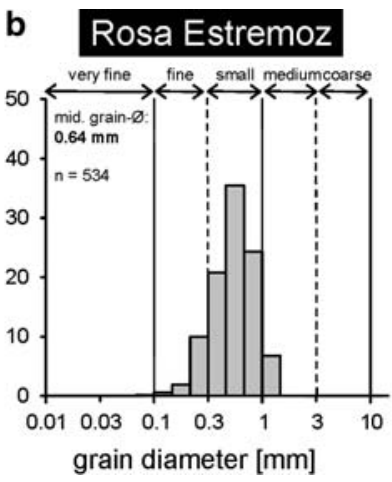

$0.6 \mathrm{~mm}$ (Fig. 6c). The long-axes of the slightly elongated show a grains are preferable oriented in the Z-direction, visible in XZ- and YZ-thin sections (Fig. 5c). Concerning the lattice preferred orientation the Carrara marble also shows the characteristics of a c-fibre type. In contrast to the other investigated marbles, the Carrara sample only exhibits an intensity of the texture around $1.3 \mathrm{mrd}$ of the $c$-axis maximum (Fig. 7).

\section{Assessment of facades}

Building measurements were made at all buildings using a modified version of the "bow meter" (Schouenburg et al. 2000; Nordtest Method 2002) to constrain whether the building physics and/or the materials themselves are the controlling parameters on the bowing. Therefore all panels were measured and compiled with respect to their compass direction, height above ground, panel face dimensions and thickness, degree in bowing, relationship between bowing and joint width as well as the anchoring system.

Frequency and distribution of bowing

The panels of the Oeconomicum building mostly exhibit a remarkable "concave inward" bowing (Fig. 8). As illustrated in Fig. 9 the degree of bowing is different at each facade. Nearly all panels are bent concave, except for the east facade where row 2 shows a clear convex bowing of about $6.8 \mathrm{~mm} / \mathrm{m}$. Row 1 of the east facade is also almost totally convex, but much weaker with a mean value of $-1.5 \mathrm{~mm} / \mathrm{m}$. The maximum value for a single panel was also registered in the east facade at row 4 with $23 \mathrm{~mm} / \mathrm{m}$. In contrast, the west and south facades exhibit a more homogeneous distribution with a low mean bowing in the lowermost row and a medium degree of bowing in row $2-4$. The lowermost parts of each facade generally show the lowest values. The north facade exhibits comparable patterns with very weak "convex outward" ones in rows $2-4$. The bowing behaviour can change from one group of panels to the next one. For aesthetic reasons the panels with 
Fig. 8 Observed damage on the investigated marble panels: a-c OEC, $\mathbf{d}-\mathbf{f}$ STD and $\mathbf{g}-\mathbf{i}$ SUB.

a The panels from the OEC are mounted with a kerf on a continuous rail at the bottom and are held by a ledge at the top. The panels clearly show a concave bowing of the Peccia marble, crack formation (b) and propagation perpendicular to the long axes of the panel and $\mathbf{c}$ a crack initiated at the upper corner of the panels; $\mathbf{d}$ Bowing of the Rosa Estremoz marble, e crack formation perpendicular to the main rock fabrics, i.e. the rock foliation and $\mathbf{f}$ crack formation parallel to the long axes of the panels which is in most cases also parallel to the foliation: the cracks are clearly visible due to the backweathering of phyllosilicate; g Clearly developed convex bowing of the Carrara marble from the SUB. $\mathbf{h}$ Crack typically initiated at the dowels and i breakout of larger marble fragments at the dowels
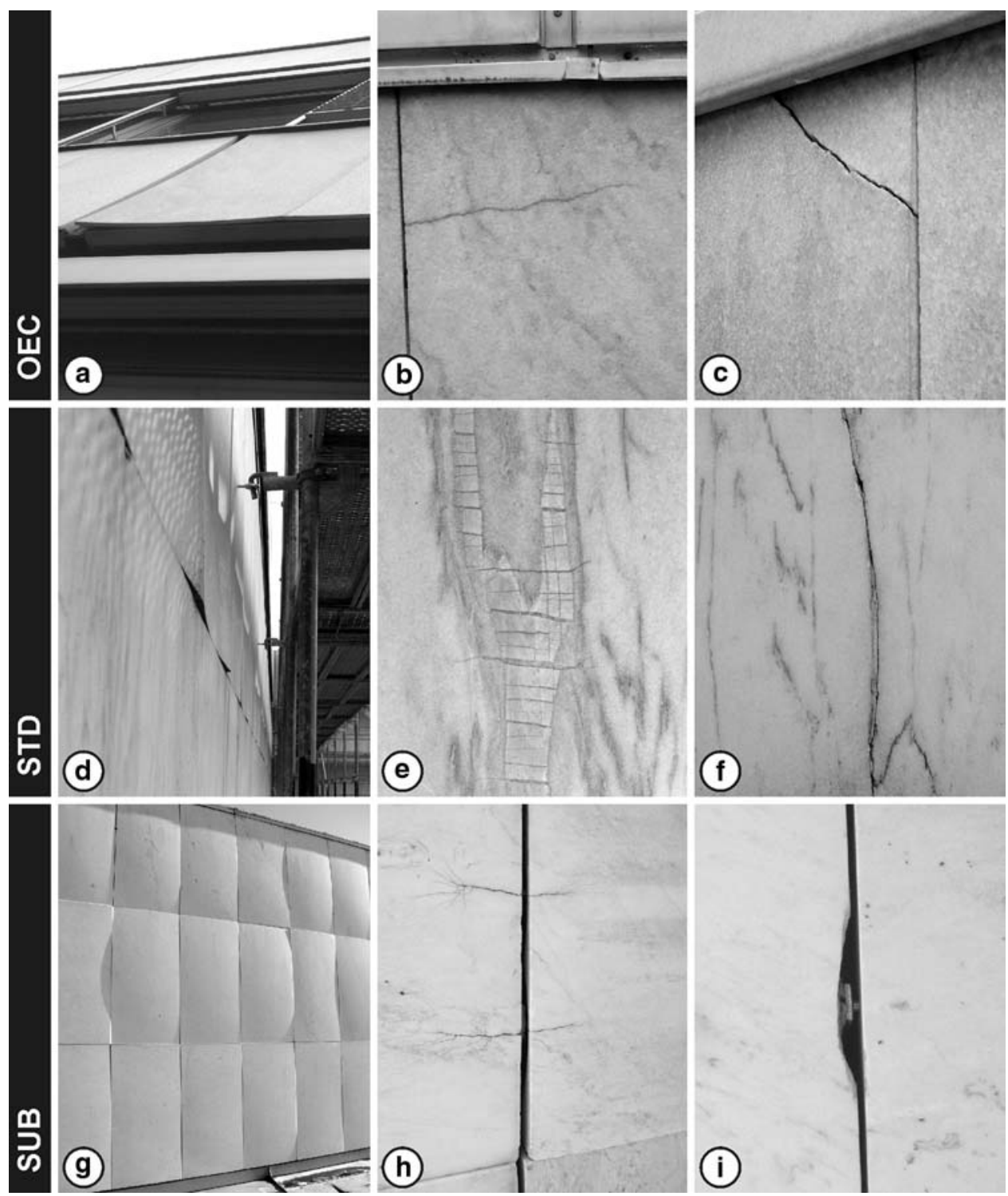

identical ornamental or decorative elements, i.e. the same cutting direction were arranged in such a way that panels with comparable structure are combined together. Therefore, the bowing behaviour at the same height changes from one group of panels to the next one. From these findings there is a causal connection between fabric anisotropies and the bowing of panels.

The panels of the State Theatre of Darmstadt are characterised by both concave and convex bowing, whereas convex bowing is predominant (Figs. 8, 10). In general, the bowing is less pronounced for most of the panels at the STD and is for the majority of cases less than $3 \mathrm{~mm} / \mathrm{m}$. Very rarely is the degree in bowing higher than $5 \mathrm{~mm} / \mathrm{m}$. The convex bowing seems to be more homogeneously distributed for the varying facade orientations and for the different rows. Conspicuously the bowing at the north and south facades show a contrary behaviour. At the north facade the lower rows exhibit stronger convex bowing, whereas the upper rows show a less pronounced deformation. For the south facade this relationship is inverted (Fig. 10). The concave bowing of slabs at the State Theatre is more complex. For example, the highest bowing values at the north and south facades are observable in row 6 and 10 exceeding $4 \mathrm{~mm} / \mathrm{m}$. A lot of these panels are below the window rows. This observation suggests that the intensity of bowing is also controlled by building physics.

Most of the panels at the State and University Library (see Figs. 8, 11) exhibit a remarkable convex bowing (see Fig. 8g) increasing with height above ground. Slight concave bowing is extremely rare and observable only in the lower parts of the cladding. After measurements of a total of 3,972 panels over the whole building, the frequency distribution of bowing values reveals a nearly Gaussian distribution (Fig. 11). The mean bowing value is $4.8 \mathrm{~mm} / \mathrm{m}$ 


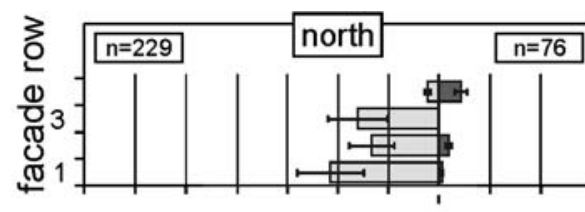
top
$\square$ concave
convex
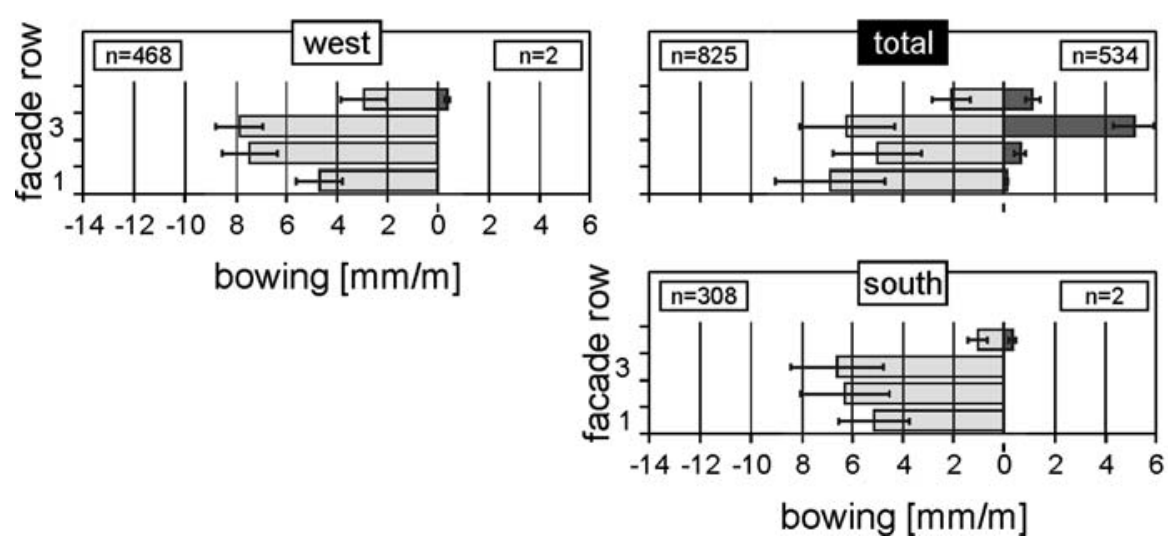

bottom

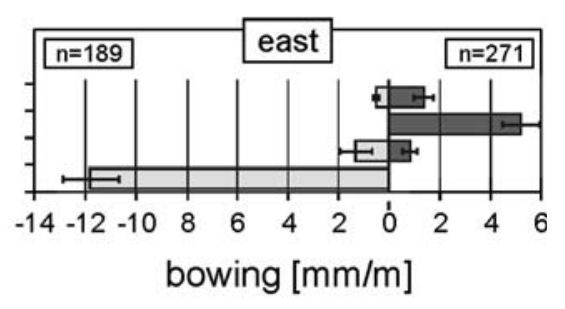

Fig. 9 Bowing of the marble panels versus facade row from the Oeconomicum (OEC) with respect to the compass direction. An average value ("total") is designated in the graph and total average value of all panels is given

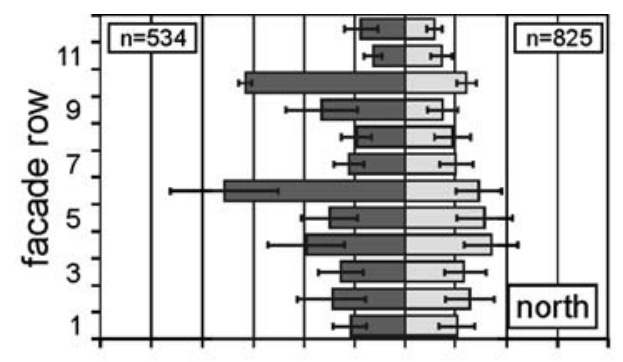

top
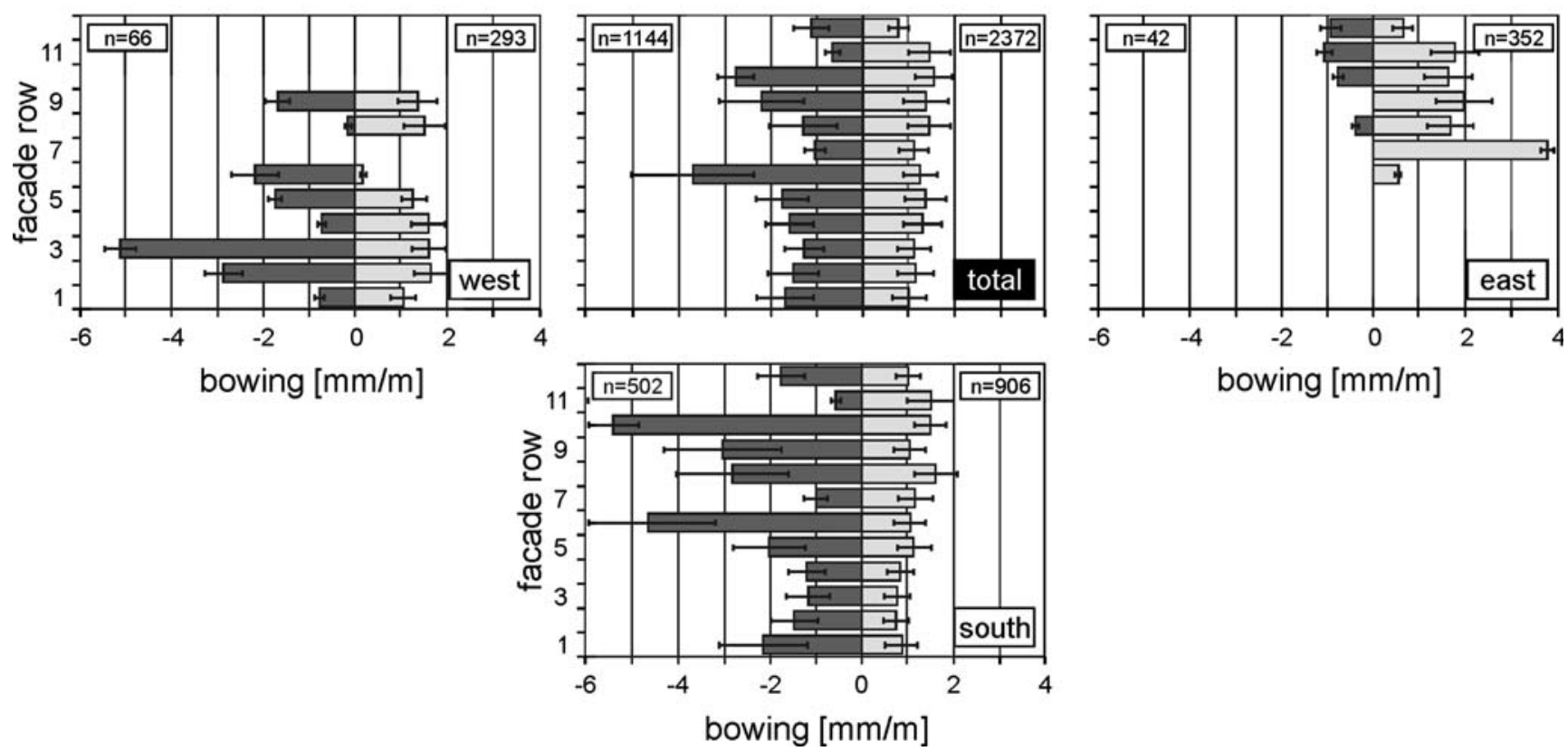

Fig. 10 Bowing of the marble panels from the State Theatre Darmstadt (STD). The bowing versus facade row is also given with respect to the compass direction. The average value for all investigated panels is shown in the graph labelled "total" 
with a standard deviation of $2.9 \mathrm{~mm} / \mathrm{m}$. A maximum value of $18 \mathrm{~mm} / \mathrm{m}$ was observed at the north facade at a panel of $72 \mathrm{~mm}$ height and $74 \mathrm{~mm}$ widths. To evaluate the data with sufficient precision, the frequency distribution was divided into bowing classes with ranges of $2 \mathrm{~mm} / \mathrm{m}$. Deformed panels were grouped into bowing classes: bowing lower than $1 \mathrm{~mm} / \mathrm{m}$ including convex as well as concave bowing belongs to the bowing class " $<1 \mathrm{~mm} / \mathrm{m}$ " and bowing higher than $11 \mathrm{~mm} / \mathrm{m}$ refers to the class " $>11 \mathrm{~mm} / \mathrm{m}$ ".

The lowermost three rows, equivalent to an altitude up to $3.75 \mathrm{~m}$, show the lowest bowing values at all the facades. There, the row averages range between concave bowing $(-0.3 \pm 1.1 \mathrm{~mm} / \mathrm{m})$ and convex bowing of $(3.8 \pm 2.5 \mathrm{~mm} / \mathrm{m})$, both observed at west facade. From row 4 to row 13 (altitude: $3.80 \mathrm{~m}$ up to $14.20 \mathrm{~m}$ ) the mean bowing tends to increase very clearly at the south facade $(4.5-7.9 \mathrm{~mm} / \mathrm{m})$ and north facade $(4.0-9.0 \mathrm{~mm} / \mathrm{m})$, and is less distinct at the west facade $(6.5-8.2 \mathrm{~mm} / \mathrm{m})$ and east facade $(4.2-5.8 \mathrm{~mm} / \mathrm{m})$. Again, the uppermost 14 th row (altitude: $14.20 \mathrm{~m}$ up to $14.90 \mathrm{~m}$ ) exhibits significant lower bowing averages except for south facade where a single maverick raises the mean value. Looking at the whole building (middle diagram of Fig. 11) the row averages from all facade orientations reflect the trend from the single facades. The row averages increase from $1.5 \pm 1.2 \mathrm{~mm} / \mathrm{m}$ in row 1 and 2 up to $6.8 \pm 2.6 \mathrm{~mm} / \mathrm{m}$ in row 13 . Quantifying the average bowing of different facade orientations, west facade exhibits the highest mean value $(6.4 \pm 3.0 \mathrm{~mm} / \mathrm{m})$; the north and south facades are slightly lower showing comparable values $(5.8 \pm 2.9 \mathrm{~mm} / \mathrm{m}$ and $5.7 \pm 2.6 \mathrm{~mm} / \mathrm{m})$, whereas the east facade displays the lowest bowing average $(4.2 \pm 1.7 \mathrm{~mm} / \mathrm{m})$.

Bowing versus visible damages

Besides the bowing the marble panels of the different buildings show numerous visible damages like cracks and outbreaks. Depending on the amplitude of bowing of the
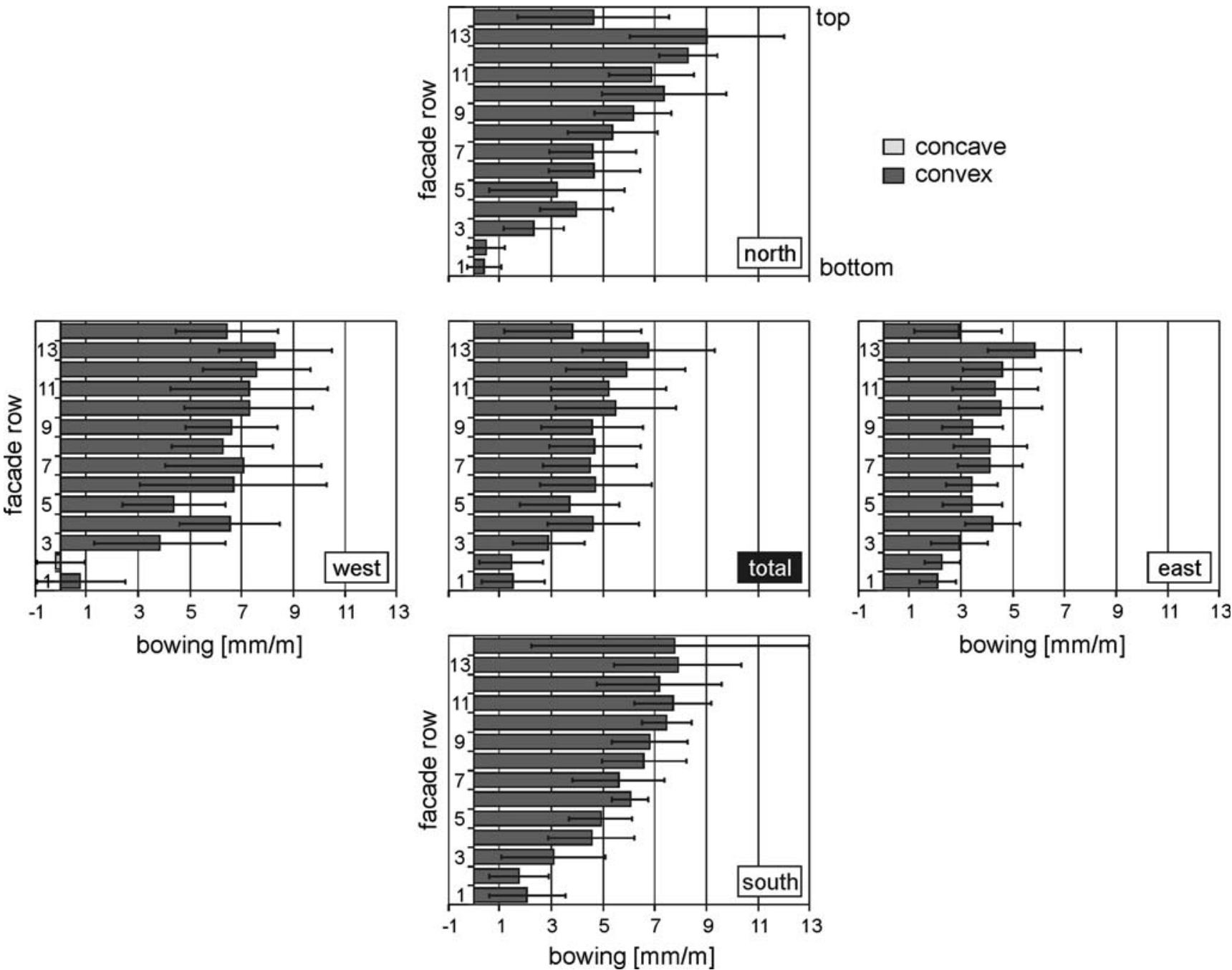

Fig. 11 Row averages of bowing values for the SUB of different facade orientations and of all facades in the (central diagram) 
OEC marble slabs, cracks occur in the upper corners up to $15 \mathrm{~cm}$ long as well as at the junctions with the kerf. At an advanced stage of deterioration these cracks can become transformed into larger scale breakouts (Fig. 8). Figure 12a gives a rough correlation between intensity of bowing and the relative frequency of visible cracks (length $>10 \mathrm{~cm}$ ) and breakouts (fracture $>10 \mathrm{~cm}$ ). From weak convex bowing (class $-2: 1 \%$ ) to strong concave bowing (class $5: 81 \%$ ) an increase in cracking occurs. Furthermore, the ratio of panels showing both cracks and breakouts increases rapidly from class $3(1 \%)$ to class $5(31 \%)$.

The marble slabs of the STD are characterised by different sets of cracks (Fig. 8). At an advanced stage of deterioration these cracks can be subdivided into foliationparallel cracks (which are parallel or subparallel to the greyish to brownish layers), cross-cutting cracks at a highangle to the foliation and cracks originating near the panel boundaries (not exclusively at the dowels). In addition, it seems that the panels with a higher degree in bowing do not show a complex crack pattern. Contrary to the OEC situation the frequency of cracking does not correlate with the amount of bowing, which is shown in Fig. $12 \mathrm{~b}$.

For the Carrara marble panels of the SUB numerous cracks also occur mostly initiated at the dowels (Fig. 8). A crack propagation longer than $5 \mathrm{~cm}$ is shown in Fig. 8h, i and observed at roof level. Large cracks and breakouts in the lowermost panel row are due to vandalism. However, the percentage of visible damages increases with the amount of bowing (Fig. 12c). Only $9.5 \%$ of the panels with a bowing less than $1 \mathrm{~mm} / \mathrm{m}$ show visible damages, whereas every fourth panel with a bowing $>11 \mathrm{~mm} / \mathrm{m}$ shows cracks or breakouts. This is not dramatic yet, since only $3.1 \%$ of the panels belong to that highest bowing class (Fig. 11).

\section{Expansion versus bowing}

From the literature it is well known that the bowing of marble panels is associated with the expansion of the marble caused by the development of microcracks and thereof increasing porosity. Since the original joint width for the SUB is known $(8 \pm 2 \mathrm{~mm})$, it is possible to determine indirectly the expansion of the panels. For this purpose 87 selected panels from a part of the south facade were chosen to evaluate the correlation between expansion and bowing. This facade sector was considered as the most appropriate one, since all panels are nearly evenly dimensioned $(104 \mathrm{~cm}$ height, $4 \mathrm{~cm}$ thickness, 74 or $78 \mathrm{~cm}$ width). The mean value of the joint widths at the bottom and at the top of each selected panel was calculated as a magnitude of the vertical expansion and connected to the bowing of the respective panel. In Fig. 13a, the row averages of joint widths and bowing values are given as a function of the height above ground (row number). Both the bowing as well as the expansion (original joint width minus measured joint width) show an increase connected with the altitude. The minimum joint width average of $3.3 \pm 0.8 \mathrm{~mm}$ can be observed in row 10 . This is by approximation equivalent to a maximum expansion average of $(8-3.3 \mathrm{~mm}) / 1.04 \mathrm{~m}=4.5 \mathrm{~mm} / \mathrm{m}$. Furthermore, a high reciprocally proportional correlation between row averages of bowing and joint width could be found (correlation coefficient of $r=-0.95$ ), which means a directly proportional correlation between expansion and bowing exists. However, this does not imply linearity between both parameters. In Fig. 13b, the same data set as in Fig. 13a has been used, this time divided into bowing classes instead of panel rows. Here, the joint width versus bowing relationship exhibits a rather exponential trend. In the weakly bowed panels, the average joint width is near the original one, whereas in the medium to strongly bowed panels it is much lower, varying in a small range from $4.9 \mathrm{~mm}$ down to $3.8 \mathrm{~mm}$. It seems that if a certain amount of expansion is reached, the bowing increases rapidly whereas the expansion or joint width, respectively, remains more or less at one level. In order to verify this assumption, the maximum expansion of panels at roof level was additionally calculated. Sixty-five of the 272 west facing panels of $1.51 \mathrm{~m}$ height belong to the highest bowing class $(>11 \mathrm{~mm} / \mathrm{m})$.
Fig. 12 The relationship of the bowing classes and the relative frequency of visible damage is presented in a OEC, $\mathbf{b}$ STD and c SUB

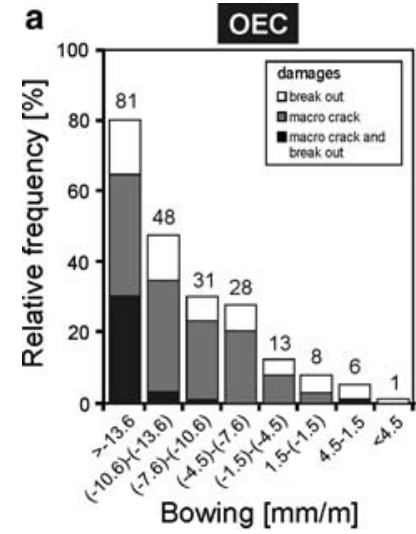

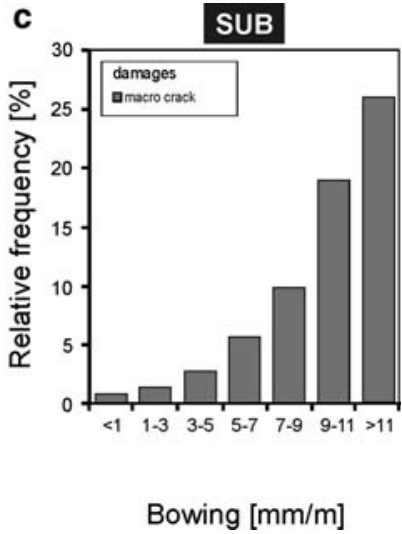


Within this group, the average bottom-top joint width is $1.5 \pm 0.8 \mathrm{~mm}$, resulting in an average expansion of $(8-$ $1.5 \mathrm{~mm}) / 1.51 \mathrm{~m}=4.3 \mathrm{~mm} / \mathrm{m}$ which is similar to the maximum expansion row average at the south facde (see above).

\section{Effect of panel size}

In order to assess the effect of different panel heights on the degree of bowing, the mean bowing values of row 7, 8, 10, 11 and 13 of the west, east and south facades were calculated for two different panel heights (Fig. 14): "small" panels with a height of 72 or $81 \mathrm{~cm}$ were measured with a measuring distance of $70 \mathrm{~cm}$, "large" panels with a height of $104 \mathrm{~cm}$ were measured with a measuring distance of $100 \mathrm{~cm}$, both along the vertical centre line. At the west facade and less pronounced at the north facade, small panels show higher bowing than large panels, whereas the relationship is reversed at the east facade (Fig. 14). The effect is not very strong since the line of equal bowing is in the range of the standard deviations of all row mean values. Nevertheless, all data points to a selected part of the facade in Fig. 14, which is either above or below the line of equal bowing so that the trend is obvious. In contrast, in the uppermost 14th row "small" panels (66 cm in height) with that of small panels in neighbouring row 13, the reduction is $28 \%$ at the west facade, $57 \%$ at the north facade and $43 \%$ at east facade.

Age of the panels

Bowing was assumed to increase with the age of the panels, and it is preliminarily assumed that these will develop, proportionally to the exposure time. Based on observations made at the Finlandia Hall in Helsinki, Mustonen et al. (1993) had proposed that bowing and strength loss is more or less linearly correlated with the age and time of exposure. However, long-term tests on the bowing velocity are still lacking. For the SUB 232 representative panels were measured in the year 2000. The average bowing for all panels was around $4.5 \mathrm{~mm} / \mathrm{m}$, while in 2003 the bowing had already increased to $5.5 \mathrm{~mm} / \mathrm{m}$ (see Fig. 15). In conclusion, the average bowing for the first 9 years of exposure was around $0.49 \mathrm{~mm} / \mathrm{m}$ per year, while from 2000 to 2003 the bowing velocity was reduced to $0.38 \mathrm{~mm} / \mathrm{m}$ per year.

Decay characteristics due to bowing

Although a considerable amount of data on the decay of marbles has been collected in the past the data is still far from complete. Bowing of marble slabs is generally associated with structural break-up, increasing porosity and loss of strength and decreasing ultrasound velocity. To examine the effect of bowing on the rock mechanical properties as well as on the rock fabric seven panels $(\mathrm{S} 0: 0.0 \mathrm{~mm} / \mathrm{m}, \mathrm{S} 1$ : $0.8 \mathrm{~mm} / \mathrm{m}, \mathrm{S} 2: 2.3 \mathrm{~mm} / \mathrm{m}, \mathrm{S} 3: 4.8 \mathrm{~mm} / \mathrm{m} \mathrm{S} 4: 6.7 \mathrm{~mm} / \mathrm{m}$, S5: $7.5 \mathrm{~mm} / \mathrm{m}$, S6: $9.3 \mathrm{~mm} / \mathrm{m}$ and $\mathrm{S} 7: 11.1 \mathrm{~mm} / \mathrm{m}$ ) from the south facade representing a broad variation of bowing were removed (Fig. 16). For comparison, one additional unbowed sample of indoor exposition was also analysed. This investigation will help to overcome the missing links and will allow a predictive model to be built, because the particular site, i.e. the environment, building physics, stone type is well known and comparable. All panels were investigated with respect to the rock fabrics and composition as well as their bowing potential.

\section{Mineralogy and fabrics}

The marble used for the cladding at the SUB is from the Carrara area and belongs to the so-called "Bianco Carrara Venato Gioia" variety. The samples (Fig. 17) show a nearly perfectly recovered grain fabric with more or less straight grain boundaries and frequent $120^{\circ}$ triple junctions. The grain size is on average $150 \mu \mathrm{m}$. Only a few grains are twinned. The macroscopically visible grey veins are more fine-grained. They show a very strong unduluose extinction and the formation of subgrains occur to such an extent that the individual grains are difficult to detect. Grain boundaries are interlobating and there is a high amount of fluid
Fig. 13 Correlation between bowing and joint width of horizontal joints at a selected part of the south facade of the SUB: $\mathbf{a}$ as a function of the height above ground; $\mathbf{b}$ as a function of the bowing class a

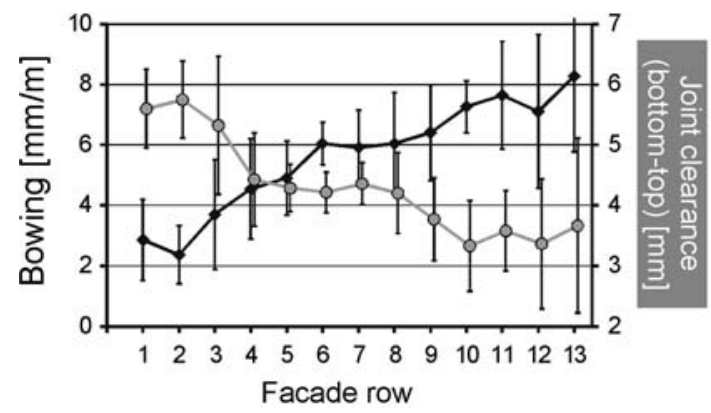

b Vertical side expansion [mm/m]

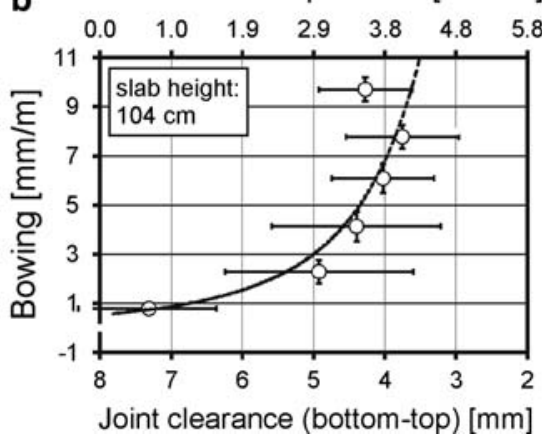


Fig. 14 Representative part of the north facade of the SUB showing different panel heights in the numbered rows (a) and (b) row averages of bowing values "small panels" versus "large" panels
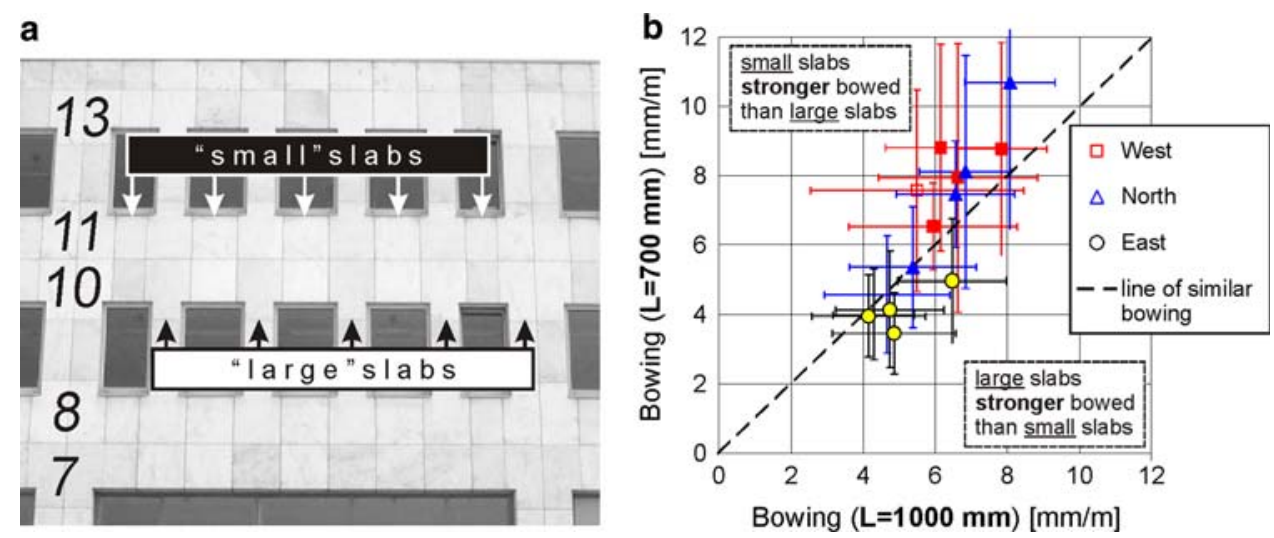

Fig. 15 Average bowing values of a representative selection of 232 facade slabs with respect to the compass direction and as a function of time. The tendency is more or less linear. The standard deviations are indicated by error bars
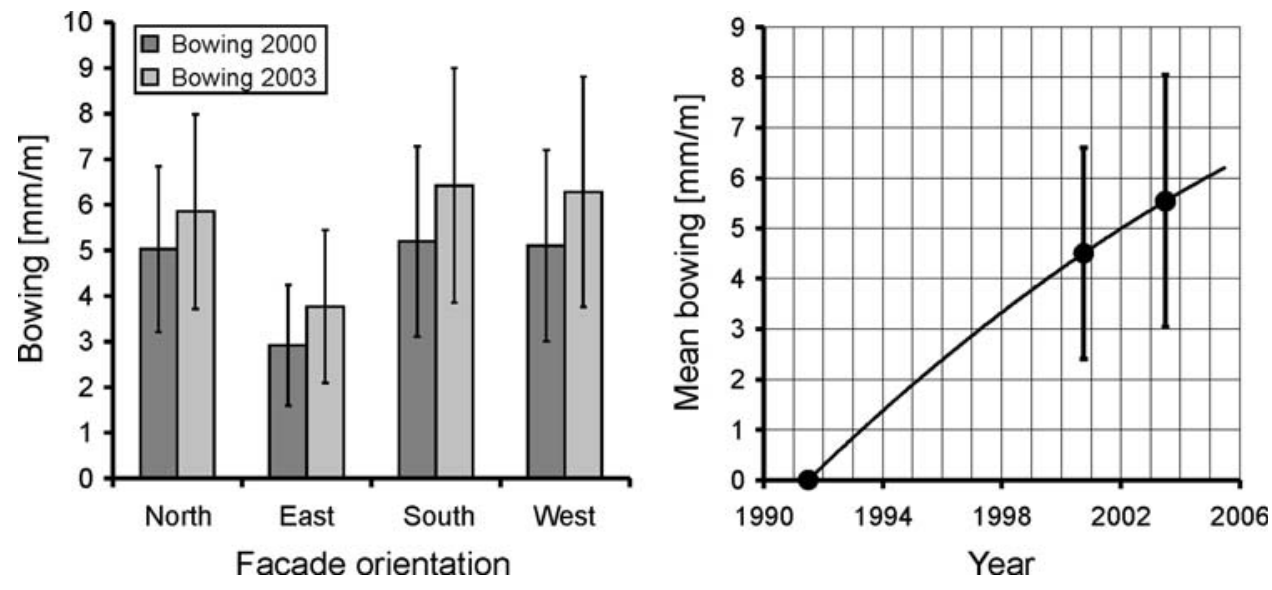

Fig. 16 a South facade of the SUB (only the position of panels S1 and S7 is indicated) and $\mathbf{b}$ shows the corresponding bowing classes of all marble panels
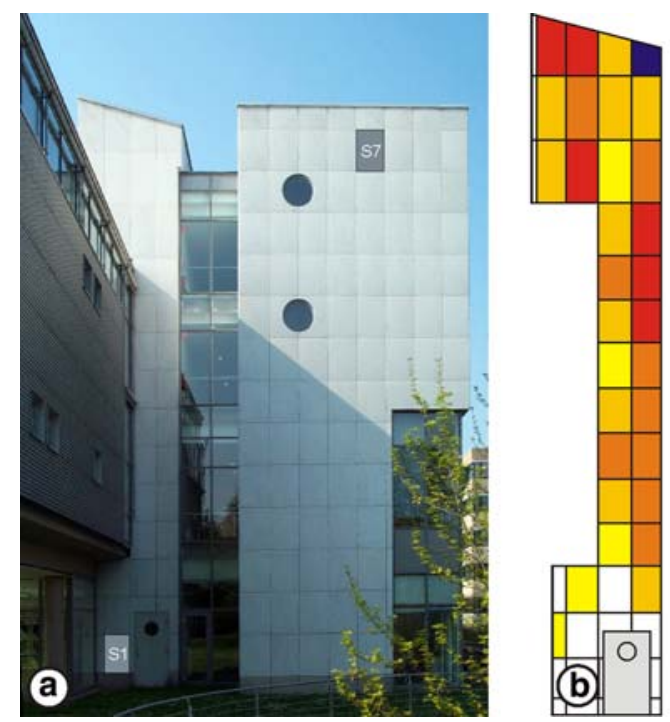

inclusions or graphite present, which is probably the cause for grey colour of the veins. Planar fabrics like metamorphic banding or foliation are difficult to discern. The increase in bowing from 1 to $11 \mathrm{~mm} / \mathrm{m}$ is also strongly evidenced by the rock fabric. The photomicrographs (Fig. 17) of the sample S7 show a significant opening along the grain boundaries (Fig. 17d). In some cases the grain boundaries start to interconnect to intergranular microcracks, i.e. the formation of a progressive network is being developed.

\section{Porosity versus bowing}

For all selected marbles (S0-S7) the porosity and pore size distribution has been determined by using mercury 
Fig. 17 Representative thin section images of the slightly deformed marble S1 (left) and the strongly deformed sample S7 (right): (a, b) overview (crossed polarizers) and (c, d) details of grain boundaries. Marble S7 is characterised by open grain boundaries due to the higher bowing of these samples compared to S1
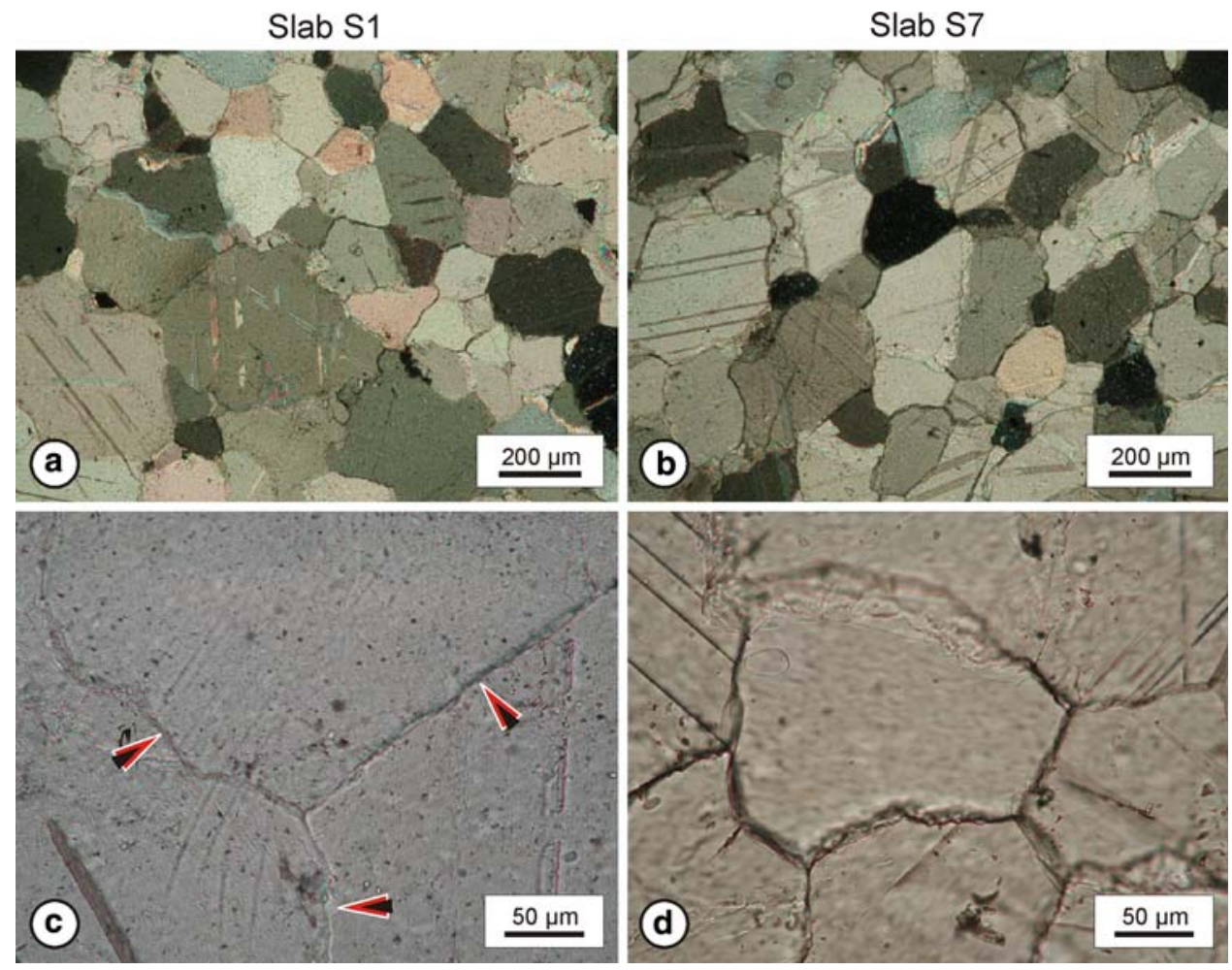

porosimetry. Figure 18 demonstrates the relationship between the porosity and pore size distribution and the degree of bowing. The indoor exposed sample S0 exhibits an initial porosity of around $0.45 \%$, while the marble S7 shows a total porosity of around $2.00 \%$, which reflects an extreme increase with respect to the usually observed values in marbles. Moreover, the pore size maximum moves towards larger pore radii with an increase in bowing. For example, sample S7 shows a significant difference in the upper pore radius range. The maximum pore diameter of this sample is around $1 \mu \mathrm{m}$, and therefore in the range of capillary pores. In contrast, the maximum pores in So are smaller than $0.1 \mu \mathrm{m}$, which cannot be filled by capillary water absorption.

\section{Rock mechanical properties versus bowing}

Flexural strength (EN 12372) and the breaking load at dowel hole (EN 13364) are basic parameters for characterising dimensional stones as a facade cladding. Examining the effect on mechanical properties (see Fig. 19) the decrease of flexural strength can be described as a potential function showing a strong reduction in the weakly bowed samples (S0 $10 \mathrm{MPa}$ ) and a less pronounced decrease in the strongly bowed slabs (S7 $<4 \mathrm{MPa})$. The same tendency is observed for the breaking load at dowel hole versus bowing (see Fig. 19), where the initial strength of sample $\mathrm{S} 0$ of $2.43 \mathrm{kN}$ is reduced to $1.35 \mathrm{kN}$ for sample
S7. In consequence, the reduction in strength for the breaking load at the dowel hole is around 54\%, while the flexural strength is much more pronounced.

\section{Discussion}

\section{Evidence from the buildings}

The studies of the marble panels lead to a number of observations on the three buildings. Initially flat panels may after a number of years develop a significant bowing. This bowing is observed for three different marble types like the Peccia marble, Rosa Estremoz and the Carrara marble. All these marble types differ in their macrostructures as well as in the rock fabrics (grain size, grain boundary configurations lattice preferred orientation, etc.). Despite the numerous existing publication on the deterioration of marbles and in particular the bowing phenomenon, no conclusive explanation concerning the driving forces or processes exists. Building physics and the local environmental were also stressed.

In the following we will briefly summarize the main observations from the buildings.

The direct comparison of the three buildings clearly shows that the bowing is not a uniform process. At the OEC the panels show mostly a concave bowing. The same holds true for the STD, while the SUB is characterised 


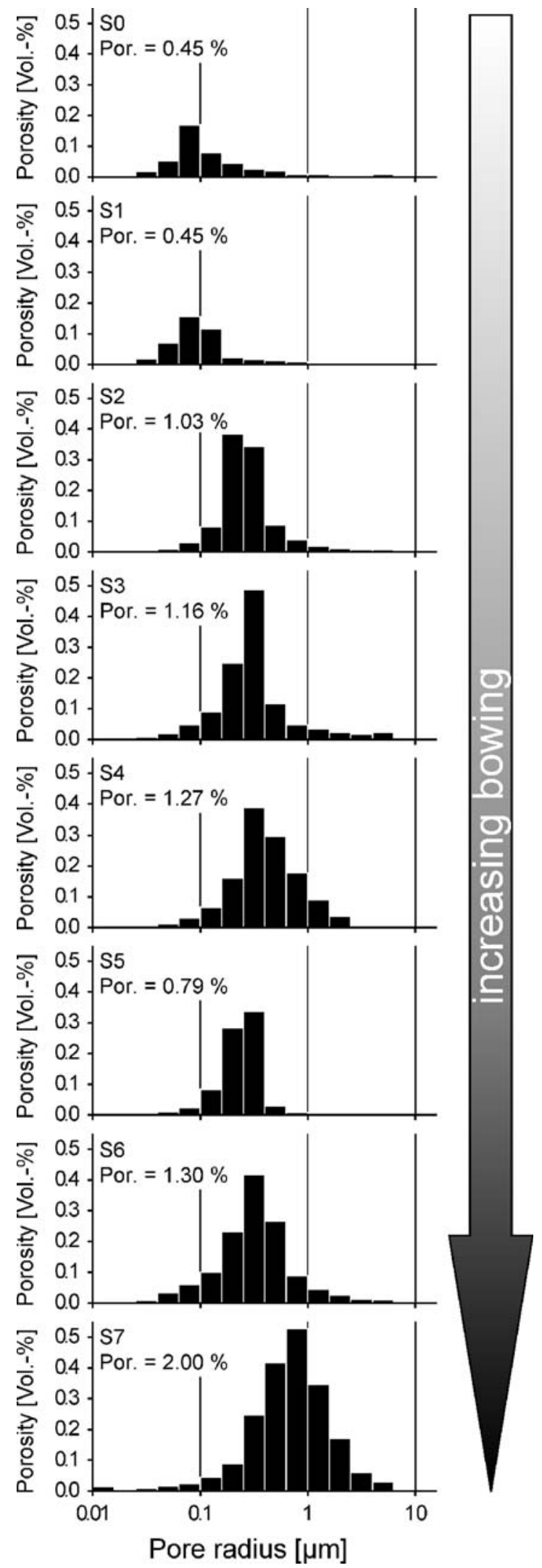

Fig. 18 Pore size distribution versus bowing of the eight demounted marble panels. The effective porosity (Por.) is also given mainly by a convex bowing. At the OEC the magnitude and orientation of bowing differs widely for the same marble type. On the north facade the different rock structures macroscopically visible on the panel surface are a result of the marble slabs being cut in different directions. The bowing is comparable for panels of the same block-cut direction, and is different when the cutting direction with respect to any rock structure changes. The degree of bowing of panels is associated with the orientation of these macroscopically visible fabric elements of the marble, since all other influencing factors are relatively constant (dimension, exposition, microclimate, building physics). The bowing varies between no bowing up to $11.5 \mathrm{~mm} / \mathrm{m}$ within the same panel row. On the Oeconomicum 35 years after construction the average calculated from 1,556 measurements is $5.55 \mathrm{~mm} / \mathrm{m}$, which means a rate of $0.16 \mathrm{~mm} /$ m per year. In contrast, the SUB, built in 1991, is clad with panels of different width, same thickness $(4 \mathrm{~mm})$ and mostly of the same height $(104 \mathrm{~cm})$. It is characterised by open joints without sealant, a ventilation gap at the rear and fixing by vertical or horizontal stainless steel dowels. Most panels show a distinct convex bowing. The on-site measurements reveal an increase of bowing intensity from bottom to top and was observed at all facades. The same observation can be made at the OEC, where the lowermost parts of each facade show the lowest degree of bowing. The average bowing values of a representative selection of panels as a function of time refer to a bowing rate that is nearly constant, approximately $0.5 \mathrm{~mm} / \mathrm{m}$ per year. The bowing intensity of marble panels at the SUB is not different between the north and south facades, and therefore less controlled by the temperature. The results point to wind velocity and moisture content in combination with temperature as controlling factors in bowing. The main wind direction in Göttingen is from the west and that the wind velocity increases with the altitude, which is in accordance with the reported bowing differences in exposure. The facade of the STD, built in 1972, is of intermediate age and shows a surprisingly lower amount of bowing except for some rows in the north, south and west compass direction. In contrast to the OEC and SUB, the amount of convex and concave bowing is more or less comparably distributed. The main difference is that the Rosa Estremoz marble from the STD exhibit a very complex crack pattern, i.e. cracks that are oriented parallel and perpendicular to the panel long axes, which is in most cases also the direction of the foliation. Therefore, the relative frequency of panels showing visible damages (cracks, breakouts) versus bowing is more or less constant for all bowing classes, while for the SUB and the OEC the degree of damages increases with the increasing bowing. Surprisingly, the panels with the highest bowing do not show 
Fig. 19 Flexural strength (a) and breaking load (b) at the dowel hole (mean values) as a function of bowing intensity. The standard deviations are indicated by error bars. The regression curves represent the progression of a potential function

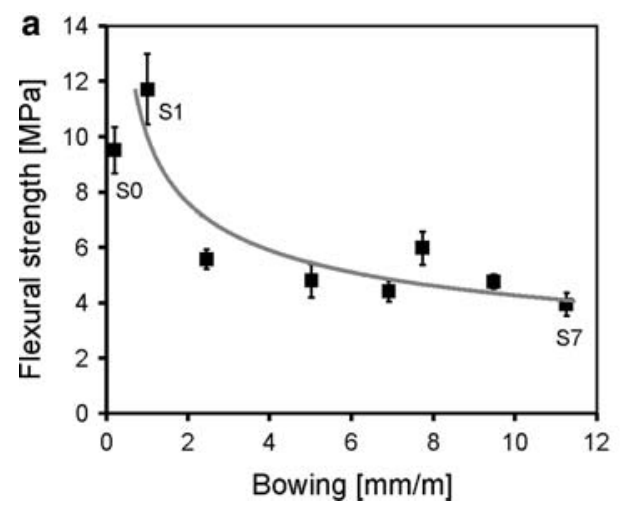

an intense state of microcracking. This observation supports, the assumption that the bowing-related stress may be accommodated by the observed crack fabrics. However the anchors used in Darmstadt and at the Göttingen buildings are of a different type. For the panel thickness and dimensions no link exists between the type of anchoring system and the bowing of the panels.

Controlling factors on marble decay and bowing

Although marbles have a very simple mineralogical composition, the physical weathering due to its extremely anisotopic physical properties seems to be essential. The rock fabric, which includes grain size, grain aspect ratio, grain-shape preferred orientation, lattice preferred orientation (texture) and the microcrack populations has a significant control on the materials behaviour.

\section{Thermal expansion}

The thermal expansion expresses the relative length change of a sample. The connection to the temperature is non-linear, i.e. the thermal expansion coefficient $\alpha$, which describes the specific length change $\left(10^{-6} \mathrm{~K}^{-1}\right)$ depends on the considered temperature interval. More than 24 different marble types worldwide were investigated (Zeisig et al. 2002). An experimentally determined polycrystalline thermal expansion behaviours of marbles as a function of a heating and subsequent cooling cycle can be classified in four overall categories: (a) isotropic thermal expansion without residual strain; (b) anisotropic thermal expansion without residual strain; (c) isotropic thermal expansion with residual strain; and (d) anisotropic thermal expansion with residual strain. In the case of the Peccia, Rosa Estremoz and Carrara marble the thermal expansion (see Fig. 20a-c) can be categorised under (d), i.e. anisotropic expansion with residual strain. However, the anisotropy is less pronounced in the case of the Carrara marble, but pronounced at a significantly high level. Thermally treated marble samples, which do not return to the initial length after cooling (i.e. the length before heat treatment), can show a residual strain even as a result of very small temperature changes, as shown for the temperature range between 20 and $50^{\circ} \mathrm{C}$ by Battaglia et al. (1993). In general, the measured relative expansion exhibits a significant increase with increasing temperature, whereas the slope for each sample may be different. Many samples show a large directional dependence of the thermal expansion as a function of temperature. Moreover, a residual dilatation can be observed after subsequent cooling down to room temperature for many samples, It ranges from 0.2 to $0.4 \mathrm{~mm} / \mathrm{m}$ and is seldom higher, but is usually smaller in the direction of $\varepsilon_{\text {min }}$. The thermal expansion coefficient $\alpha$ of calcite is extremely anisotropic (Kleber 1959): $\alpha_{11}=26 \times 10^{-6} \mathrm{~K}^{-1}$ parallel and $\alpha_{22}=-6 \times 10^{-6} \mathrm{~K}^{-1}$ perpendicular to the crystallographic $c$-axis, i.e. calcite contracts normal to the $c$-axis and expands parallel to the $c$-axis during heating.

\section{Thermal expansion and modal composition}

The modal composition is an important factor for the thermal properties of a marble, since the thermal expansion behaviour is at least partially controlled by the single crystal properties (Grimm 1999; Weiß et al. 1999). Both calcite and dolomite show an extreme directional dependence of $\alpha$ at different crystallographic directions. Parallel to the $c$-axis, both minerals show an $\alpha$ value of about $26 \times 10^{-6} \mathrm{~K}^{-1}$. However, parallel to the $a$-axis dolomite shows a positive $\alpha$ value about $6 \times 10^{-6} \mathrm{~K}^{-1}$. Thus, even strongly anisotropic dolomite marbles will not show any contraction with increasing temperature. Since dolomite and calcite marbles may show a comparable thermal degradation, the residual strain is not likely to be controlled exclusively by the composition. Marbles with large grain size exhibit the same magnitude of residual strain as marbles with a smaller grain size. Therefore, the grain size cannot be the most important factor for marble degradation (see discussion in Zeisig et al. 2002) as was suggested by Tschegg et al. (1999). The grain shape anisotropy significantly triggers the thermal degradation, as shown for 

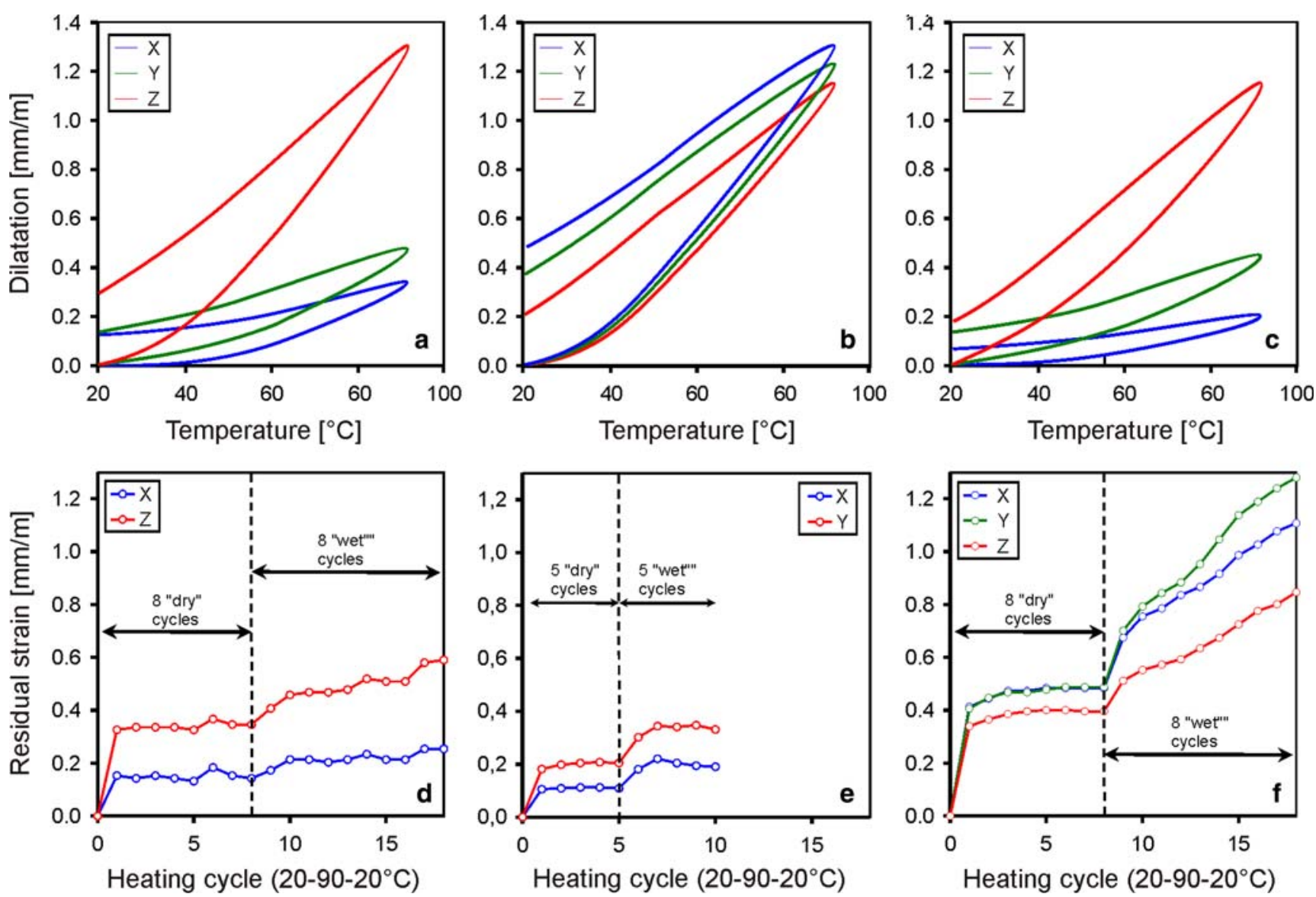

Fig. 20 Thermal dilatation $(\mathbf{a}-\mathbf{c})$ as a function of temperature, given in three orthogonal directions. a Peccia, b Rosa Estremoz and c Carrara. d-e Progressive increase of residual strain of the marbles

investigated as a function of the number of heating cycles under dry ( 5 or 8 cycles) and wet conditions: d Peccia marble, e Rosa Estremoz and $\mathbf{f}$ Carrara marble

several samples by Siegesmund et al. (2000) or Ruedrich et al. (2001). Thus, grain boundary cracking is the most prominent factor for marble degradation; a substantial part of the observed directional dependence of residual strain must be attributed to shape fabrics. The irregularity of grain boundaries (Fig. 4) does not play such an important role (e.g. Zeisig et al. 2002), which in part contradicts the observations by Royer-Carfagni (1999) or Grelk et al. 2004. Marbles with interlobate fabrics as well as marbles with polygonal fabrics may show a residual strain after thermal treatment. Any ongoing quantitative studies are still lacking.

The lattice preferred orientation (texture) clearly determines magnitude and directional dependence of $\alpha$, since there is a general agreement between calculated (texturebased) and experimentally determined anisotropies. Thermal degradation changes this relation, i.e. the anisotropies increase or decrease according to a coincidence or contrariness of thermal degradation and intrinsic dilatation, respectively. A general observation is that the maximum of thermal degradation is closely linked to the $c$-axis maximum of the calcite crystals A deviation from this behaviour

is correlated with the shape-preferred orientation. The individual grain to grain orientation, i.e. the misorientation, may produce internal stresses leading to microcracking (e.g. Tschegg et al. 1999 or Weiss et al. 2003). This could occur by an almost random orientation of the grains or even in the case of a strong preferred orientation. However, the total amount of thermally-induced microcracking must be validated in the future by single grain texture measurements and modal calculations (see Weiss et al. 2004). The total anisotropy for a monomineralic rock has to be between an isotropic situation (random orientation of all crystals) and a situation of maximum anisotropy, where all crystals have the same crystallographic orientation which corresponds to the single crystal anisotropy. Consequently, the thermal expansion should be mainly controlled by the degree of a crystallographic preferred orientation (texture) of the calcite crystals. A significant amount of the residual strain can also be observed for marbles after heating up to $90^{\circ} \mathrm{C}$, which also seems to be controlled by the texture.

Pre-existing microcrack systems may be of importance as well (Weiß et al. 2001; Weiss et al. 2002a, b). Siegesmund et al. $(1999,2000)$ have shown that a change in the 
anisotropy patterns between modelled and experimentally determined values may be explained by pre-existing microcracks, resulting from a complex geological history.

\section{Evidence from finite-element modelling}

Microstructure-based finite element simulations were used by Weiss et al. (2002a, b, 2003, 2004) providing an excellent insight into the magnitude and mechanisms of thermal degradation. The basic observation is that the thermal expansion behaviour of marbles can be modelled with a good coincidence to real experiments. The onset and magnitude of thermal microcracking varies for calcite and dolomite marbles, when the microstructure and texture are assumed to be the same. In each case the thermally-induced microcracking will be greater for calcite marbles. Thus, finite element modelling indicates that dolomite marbles may be more resistant against thermal weathering than calcite marbles. The variations in the texture may significantly affect the distribution of thermal stresses within the marble. There is a strong inverse correlation between thermal stresses and degree of texture, since higher elastic strain energies are associated with weakly textured marbles, and vice versa.

Grain to grain orientation relationships, frequently called misorientations, and their distributions are also important parameters. From a statistical point of view, the same bulk texture may be achieved when the grains have smaller or higher angles in between. Different misorientations lead to variations in the elastic energy density, which are on the same order of magnitude than those related to the texture itself (Weiss et al. 2003). Thus, more information on misorientations is required in the future in order to constrain thermal stresses in marble.

In summary, it can be stated that there is a clear fabric dependence of residual strain after thermal treatment and, thus of thermal degradation. Thermally induced microcracks lead to a residual strain after heat treatment and, thus, to a deterioration of the rock quality. The degradation is controlled by an interaction of all fabric patterns.

Many authors (e.g. Sage 1988 or Koch and Siegesmund 2004) can demonstrate that the increase of residual strain stops after a few heating cycles if moisture is absent. Therefore, Bucher (1956) or Winkler (1994) point out the importance of moisture in the bowing process.

\section{The effect of moisture}

To determine the effect of moisture, more detailed measurements of progressive residual strain on the Peccia, Rosa Estremoz and Carrara marbles, were performed. Five or eight dry cycles up to $90^{\circ} \mathrm{C}$ were followed by additional wet cycle's, whereby the first six wet cycles were carried out in a way that at the end of a heating cycle, the samples in the climate chamber were run until totally dry (see Fig. 20d-f).

The findings from this approach are: (1) The progressive residual strain indeed proceeds continuously; the increase is constant even after 25 cycles under wet conditions. (2) The moisture content after heating cycles apparently influences the intensity of marble degradation (Fig. 20). The strain versus cycles curve (Fig. 20) tends to get flat as long as water is still available after cooling down. As soon as the samples totally dry up after each heating cycle, the durable marble expansion accelerates again. This observation cannot be explained sufficiently by the theory of Winkler (1994) that oriented molecule layers (thickness of 2-3 nm) in capillaries $<0.1 \mu \mathrm{m}$ may cause swelling by elongation and stone disruption. As a result he concludes that panels start to bow outwards if the sun and high humidity exposes the panel from the outside only, and inwards if moisture is available behind the panel in a closed cavity where the relative humidity can remain near $100 \%$. In addition, the bowing potential of the same marble was tested in the laboratory. The test is performed is such away that the marble specimen (slab of $400 \mathrm{~m} \times 100 \mathrm{~mm} \times 30 \mathrm{~mm}$ ) was exposed to moisture on one side and infrared heating on the reverse side. The applied temperature ranged between 20 and $80^{\circ} \mathrm{C}$ and a total of 40 cycles was performed. The permanent length change and the effect of anisotropic bowing with the applied cycles are clearly demonstrated in Fig. 21.

\section{Bowing potential and risk analysis}

For an ongoing risk assessment the question arises what are the main causes on the bowing and its degree versus time and exposition. From the results of the building mapping itself, it turns out that the building physics and the material as well as the environment may have a significant control of the deterioration as well as the bowing behaviour of the marble. To determine the bowing potential and its directional dependence slabs of $40 \times 10 \times 3 \mathrm{~cm}$ were exposed to moisture on one side and heating cycles $\left(20-80-20^{\circ} \mathrm{C}\right.$ per day) on the reverse side simulating in an extreme way the conditions at the building.

\section{Artificial aging and characterisation of the bowing potential}

Simulating the conditions of marble panels at the building in an extreme way, the bowing potential was tested in the laboratory on marble slabs of $400 \times 100 \times 30 \mathrm{~mm}$ (e.g. Schouenburg et al. 2000 or Koch and Siegesmund 2004). In the case of the University Library eight panels (see Fig. 16) from the building were removed for the artificial bowing 
a
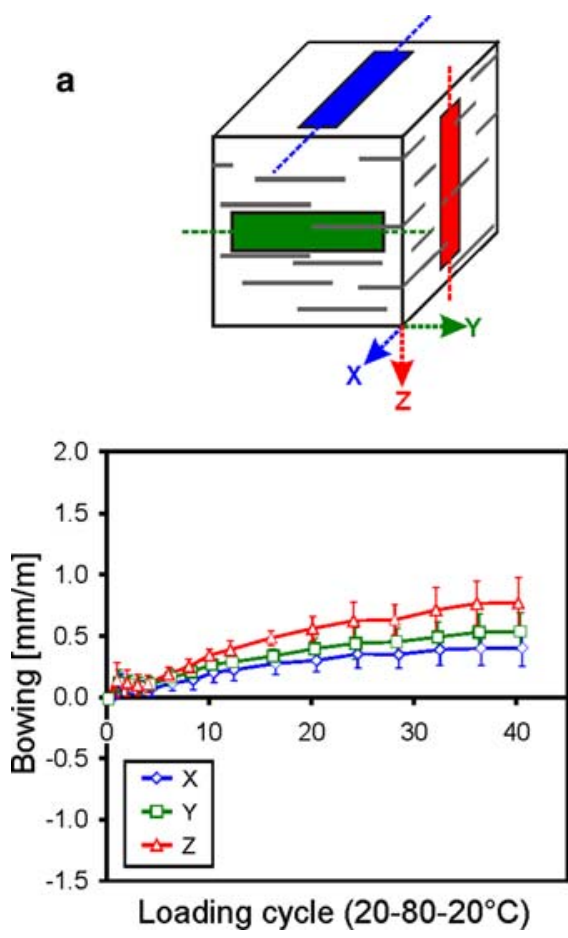

b
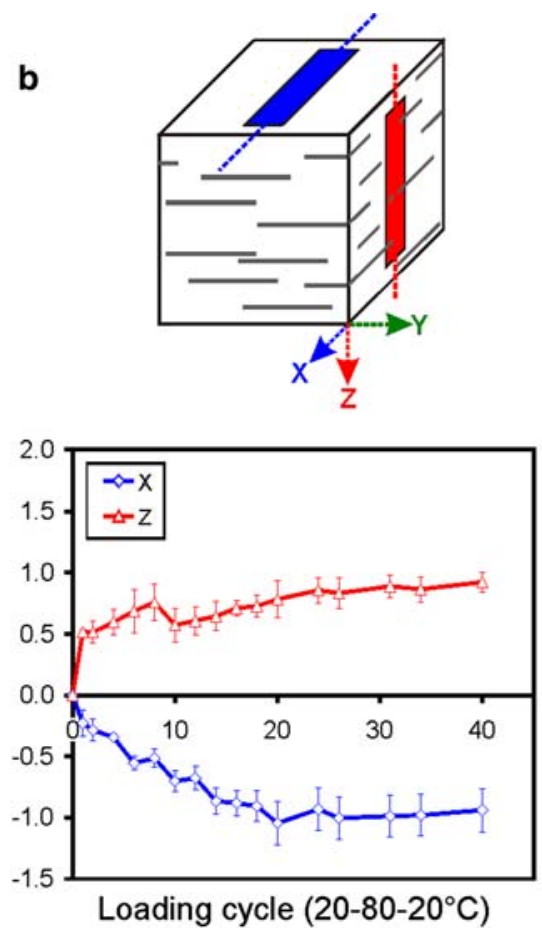

c
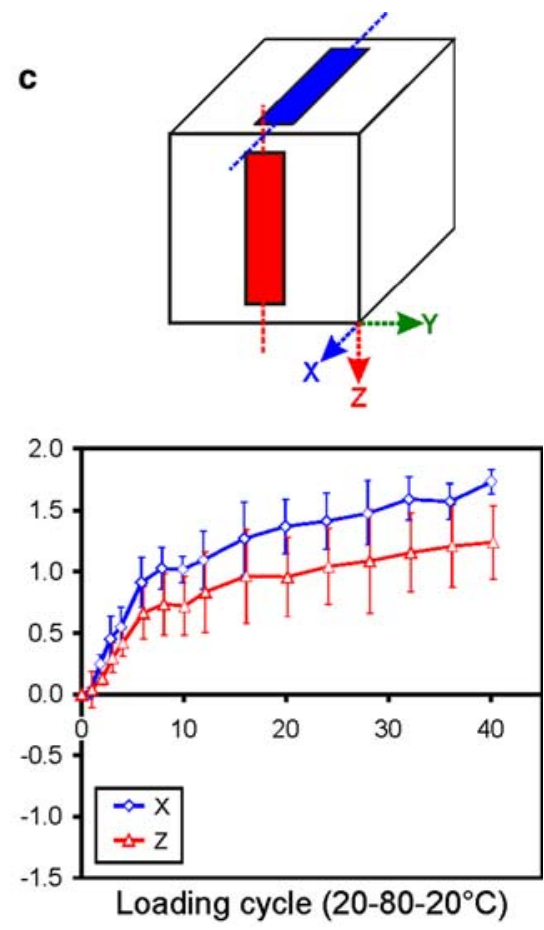

Fig. 21 Bowing of marble slabs versus number of heating cycles: a Peccia marble, b Rosa Estremoz and c Carrara marble. Each curve represents the mean bowing trend of three slabs. The different curves

test. The samples S0-S7 differ in the degree of bowing from 0.8 to $11.1 \mathrm{~mm} / \mathrm{m}$, respectively, while the panel $\mathrm{S} 0$ was completely undeformed due to its indoor exposition. From six demounted panels three specimens were investigated. The specimens were exposed to moisture on one side lying on a mm-thick film of demineralised water, and cyclical heat from a heating pad $3 \mathrm{~cm}$ above the slab surface on the reverse side. One cycle included a heating period of $5 \mathrm{~h}$, where the surface finally reached $80^{\circ} \mathrm{C}$ and a cooling period of at least $12 \mathrm{~h}$, so that the duration of one cycle was an average 1 day. The bowing was measured by means of a measuring bridge with an accuracy of $1 \mu \mathrm{m} /$ $35 \mathrm{~cm}$ every first to fourth cycle. A total of 40 cycles was performed (see Koch and Siegesmund 2002, 2004; Grelk et al. 2004). The bowing test was done to demonstrate how the increase in bowing of the panels controls the loss in strength (flexural strength and breaking load at the dowel hole), and may be used to constrain any risk management.

\section{Degree in bowing during temperature/moisture cycling and related strength properties}

All samples start to bow in a "convex" way (Fig. 21). The deterioration rate detected in the bow test differs widely between the samples (Fig. 22). For example, sample S7 exhibits the smallest increase after 40 cycles with $0.75 \mathrm{~mm} / \mathrm{m}$. The highest change $(3.62 \mathrm{~mm} / \mathrm{m})$ is observed are related to the cut-directions displayed in the cube sketch. X, Y and $\mathrm{Z}$ indicate the long axes of the test specimens. Positive values mean convex bowing, negative ones concave bowing

for sample $\mathrm{S} 1$ that corresponds to an irreversible length change of up to $1.1 \mathrm{~mm} / \mathrm{m}$. Panel S7 which has the highest value of bowing at the building shows the smallest increase in bowing after 40 cycles at laboratory conditions (Fig. 22). In fact, the samples S0 and S1 show an increase in bowing of 2.4 and $3.9 \mathrm{~mm} / \mathrm{m}$, respectively, while the sample $\mathrm{S} 7$ only shows an increase of about $1.4 \mathrm{~mm} / \mathrm{m}$.

In accordance with observations from many other authors (e.g. Jornet and Ruck 2000; Jornet et al. 2002; Koch and Siegesmund 2004, etc.), flexural strength decreases significantly under artificial weathering (Fig. 23a). After the thermo-hygric weathering all slabs exhibit a pronounced reduction in flexural strength and breaking load at the dowel hole (Fig. 23b). The decrease in the flexural strength after 40 cycles is at minimum $(26 \%, \mathrm{~S} 3)$ and at maximum $(42 \%, \mathrm{~S} 7)$. The observed reduction in the breaking load at the dowel hole varies between $13 \%$ (S7) and 33\% (S0). To summarise, the evidence clearly shows a loss in rock strength due to the bowing (Fig. 23).

\section{Conclusions}

Although marble has a very simple mineralogical composition, i.e. calcite or dolomite, the weathering features are variously shaped. In the case of the physical weathering of marbles the phenomena may range from 
Fig. 22 Time dependent increase of bowing of the six investigated facade panels during exposition at the building and after 40 heating cycles
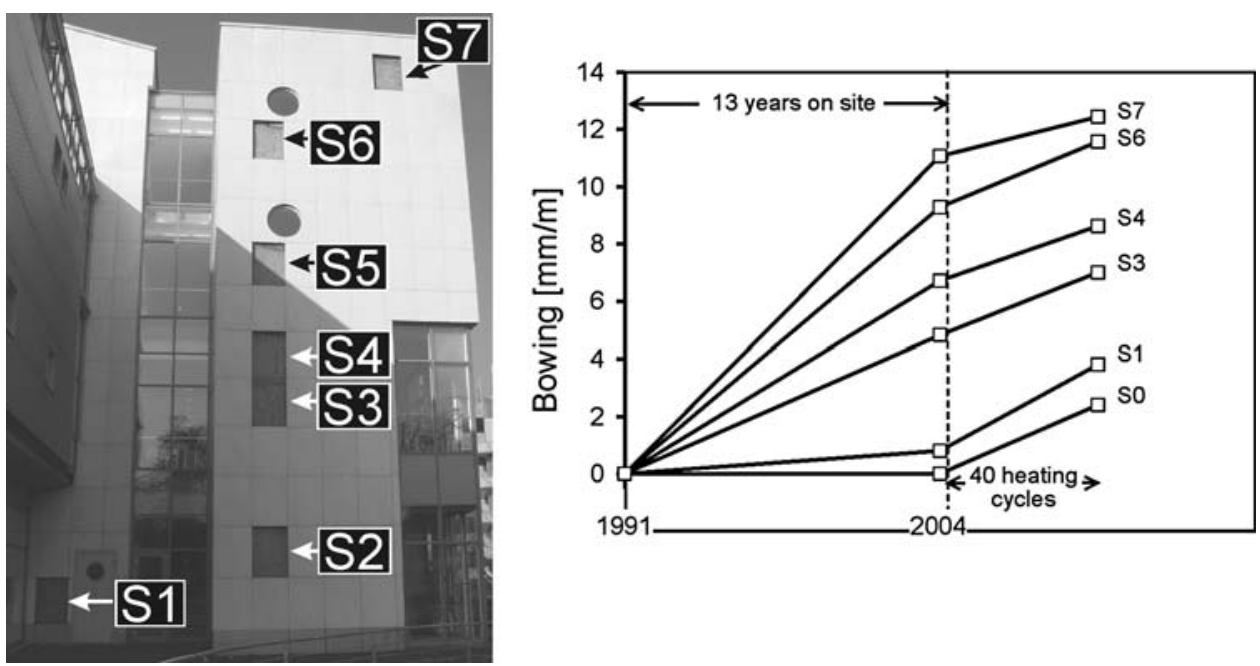

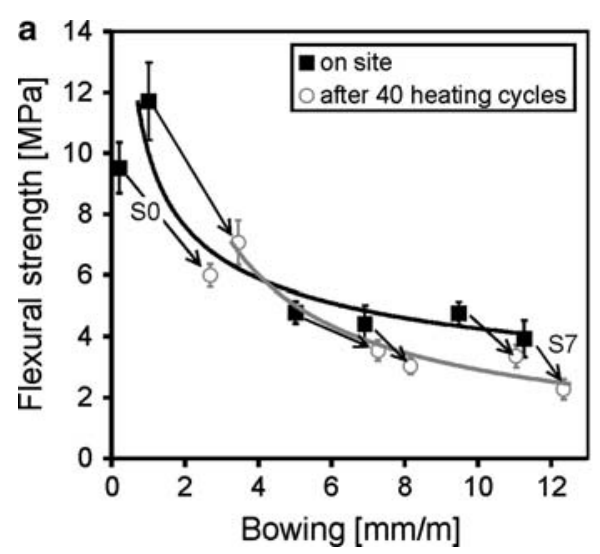

Fig. 23 Calculated ratios of a flexural strength versus bowing and $\mathbf{b}$ breaking load at the dowel hole versus bowing of the panels before (solid line) and after the 40 heating cycles (dashed line). The standard deviations are indicated by error bars superficial disintegration to complete loss of cohesion along grain boundaries due to dilatancy, i.e. the total decay of the material. The bowing of marble panels is the most spectacular deterioration feature, although the loss in cohesion and the loss in strength is already evident without any bowing. Some of the mechanisms that have been suggested to explain the bowing of marble slabs, include marble type and its fabrics, stress relief, thermal expansion and expansion due to moisture and temperature (thermo-hygric properties) or the building physics and the climate.

1. The bowing was observed at all three investigated buildings independent from the marble type (Peccia, Rosa Estremoz and Carrara). The degree in bowing is not directly correlated with the compass direction, i.e. the exposition. It seems that the bowing increases with the height of the building, but this is not true in general. The panel sizes could be of critical importance, but also smaller and thicker panels may show a somewhat higher degree in bowing already after a very short time of exposure.
2. The degree in bowing seems to control the degree of visible damages. Depending on the amount of bowing, panels may show cracks or breakouts mostly initiated at the dowels.

3. The marbles used for the cladding of the three investigated samples differ in their microstructure (lattice preferred orientation, grain size, grain shape, grain shape fabrics, grain interlocking, etc.).

4. The grain boundary configuration gives evidence that the Peccia marble shows seriate interlobate fabrics, the Rosa Estremoz marble is characterised by mainly seriate and polygonal to interlobate grain fabrics while the Carrara has a nearly equigranular-polygonal foam structure. This observation contradicts the often used statements that only polygonal (granoblastic) grain boundaries may bow. In addition, the smaller as well as the coarse-grained marbles show a significant bowing.

5. The lattice preferred orientation is one critical parameter which clearly controls the intensity of marble deterioration and in particular the degree in 
bowing. Especially for the Oeconomicum it was clearly observed that the fabric element and the bowing is linked. The ornamental pattern of facade panels in the investigated rows was due to different block-cut directions and is connected to different orientations of the foliation. It is obvious from these findings that there is a causal connection between the fabric and the amount of bowing.

6. All samples generally exhibit a pronounced increase of residual strain after heating/cooling cycles, which is directionall dependent controlled by the rock fabrics. In accordance with findings from the literature the irreversible residual strain of marbles under cyclical heating decreases after the first cycle under dry conditions.

7. The residual strain increases significantly if water is present. This behaviour is also directionally dependent and could have been controlled by the rock fabrics. The amount of residual strain under dry conditions does not necessarily correlate directly with the amount of residual strain after wet conditions.

8. The bowing potential investigated at laboratory conditions clearly supports the observation from the building mapping and the thermal expansion measurements. The bowing intensity is different for all the investigated marbles, but is significant and increases with heating-cooling cycles. Moreover, the bowing also shows a clear correlation with the rock fabrics. The progressive increase of residual strain strongly correlates with the bowing potential obtained from the laboratory bow test which reveals a close connection between expansion and bowing. A certain amount of bowing might be due to the restriction of expansion by the anchoring which would explain the observed expansion limit.

9. Investigation from buildings suggests that the laboratory bow test is an applicable method to simulate the bowing behaviour under real conditions.

10. The flexural strength as well as the breaking load at the dowel is also clearly controlled by the bowing intensities. The decrease of the mechanical properties with the bowing is significant but non-linear. Strength loss versus bowing relationship is representative for all facade panels at the buildings.

11. A conclusive result was obtained by combining the effect of bowing and its degree with the loss in strength. Several samples representing a broad variation of bowing $(<1 \mathrm{~mm} / \mathrm{m}$ up to $11 \mathrm{~mm} / \mathrm{m})$ were used for ongoing bowing potential tests to constrain the bowing rate and its control on the strength properties.

12. The strong decrease of flexural strength and the breaking load at the dowel hole after 40 additional heating cycles varies between 26 and 42\%. By examining the bowing rate from the laboratory with the average bowing rate from the buildings the laboratory ones are a little bit higher.

13. The observations from the building and the laboratory also show that any simple marble type/bowing or bowing rate correlation is missing. For example, in the case of the Rosa Estremoz marble the bowing intensity is less pronounced at the building and in the laboratory, while the progressive strain may be accommodated by a progressive crack initiation and crack growth. This is also supported from the building mapping where panels with a higher bowing do not show any cracks, while the panels with a lower degree in bowing show a higher amount of cracks and breakouts. This observation may also support the explanation of Logan et al. (1993) and Logan (2004) referring the bowing to the anomalous expansion-contraction behaviour of crystalline marble and the release of locked-in residual stresses. Finally, the observed cracks also control the mechanical properties significantly.

14. In the case of the investigated Carrara samples a more uniform relationship between the observed amount of bowing at the building and those produced by experimental bowing was achieved. In addition, a systematic loss in strength with bowing was demonstrated.

15. In summary, the combination of the building mapping with respect to the building physics and the exposure and the intrinsic properties of the rock (mineralogy and rock fabrics) as well as the laboratory bowing test are an excellent tool for the prediction of service life of marble claddings. Especially the artifical weathering under the thermohygric conditions (bowing potential test) is a careful examination for a ongoing risk analysis in combination with a monitoring system.

Acknowledgments The support of the Gebäudemanagement of the University Göttingen, the Hessisches Baumanagement Darmstadt, the EU-Project and of the EU-project "Testing and Assessment of Marble and Limestone" and of the BMBF are gratefully acknowledged. The authors are very grateful for the constructive review by John Logan.

Open Access This article is distributed under the terms of the Creative Commons Attribution Noncommercial License which permits any noncommercial use, distribution, and reproduction in any medium, provided the original author(s) and source are credited.

\section{References}

Battaglia S, Franzini M, Mango F (1993) High sensitivity apparatus for measuring linear thermal expansion: preliminary results on the response of marbles. Nuovo Cimento C 16:453-461 
Bucher WH (1956) Role of gravity in orogenesis. Bull Geol Soc Am 67:1295-1318

Bortz SA, Erlin B, Monk CB (1988) Some field problems with thin veneer building stones. In: Donaldson B (eds) New stone technology, design and construction for exterior wall systems. American Society of Testing and Materials, Philadelphia, pp 1131

Cohen JM, Monteiro PJM (1991) Durability and integrity of marble cladding. A state-of-the-art review. J Perform Construct Facil 5:113-124

Grelk B, Goltermann P, Schouenborg B, Koch A, Alnaes L (2004) The laboratory testing of potential bowing and expansion of marble. In: Prikryl R (ed) Dimension stone. Taylor \& Francis, London, pp 253-259

Grimm WD (1999) Beobachtungen und Überlegungen zur Verformung von Marmorobjekten durch Gefügeauflockerung. In: Siegesmund S, Snethlage R, Vollbrecht A, Weiss T (eds) Marmor-Konservierung. Z dt geol Ges 150:195-236

Jornet A, Rück P (2000) Bowing of Carrara marble slabs: a case study. In: Proceedings of the international congress "QuarryLaboratory-Monument”, Pavia, 2000, pp 355-360

Jornet A, Teruzzi T, Rück P (2002) Bowing of Carrara marble slabs: comparison between natural and artificial weathering. In: Prikryl R, Viles H (eds) Understanding and managing of stone decay. Carolinum Press, Prague, pp 161-170

Kessler DW (1919) Physical and chemical tests on the commercial marbles of the United States. Government Printing Office, Washington

Kleber W (1959) Einführung in die Kristallographie. Berlin

Koch A, Siegesmund S (2002) Bowing of marble panels: on-site damage analysis from the Oeconomicum building at Goettingen (Germany). In: Siegesmund S, Weiss T, Vollbrecht A (eds) Natural stones, weathering phenomena, conservation strategies and case studies, special publications 205. Geological Society, London, pp 291-306

Koch A, Siegesmund S (2004) The combined effect of moisture and temperature on the anomalous expansion behaviour of marble. In: Siegesmund S, Viles H, Weiss T (eds) Stone Decay Hazards. Environmental Geology 46:350-363

Leiss B, Ullemeyer K (1999) Texture characterisation of carbonate rocks and some implications for the modeling of physical anisotropies, derived from idealized texture types. In: Siegesmund S, Snethlage R, Vollbrecht A, Weiss T (eds) MarmorKonservierung. Z dt geol Ges 150:259-274

Logan JM (2004) Laboratory and case studies of thermal cycling and stored strain on the stability of selected marbles. In: Siegesmund S, Viles H, Weiss T (eds) Stone Decay Hazards. Environmental Geology 46:456-467

Logan JM, Hadedt M, Lehnert D, Denton M (1993) A case study of the properties of marble as building veneer. Int J Rock Mech Min Sci Geomech 30:1531-1537

Mustonen J (1993) Finlandia-Talon julkisivujen korjaus. Rakennusinsinööri-päivät, RIL K160-1993, pp 61-68

Nordtest Method NT BUILD 499 (2002) Cladding panels: test for bowing. Nordtest project 1443-99/2

Ondrasina J, Kirchner D, Siegesmund S (2002) Freeze-thaw cycles and theri influence on marble deterioration: a long term experiment. In: Siegesmund S, Weiss T, Vollbrecht A (eds) Natural stones, weathering phenomena, conservation strategies and case studies, special publications 205. Geological Society, London, pp 9-18

Rosenholtz JL, Smith DT (1949) Linear thermal expansion of calcite, var. Iceland spar, and Yule Marble. Am Mineral 34:846-854

Royer-Carfagni G (1999) On the thermal degradation of marble. Int J Rock Mech 36:119-126
Ruedrich J (2003) Gefügekontrollierte Verwitterung natürlicher und konservierter Marmore. Dissertation, Universität Göttingen, 158 $\mathrm{S}$

Ruedrich J, Weiß T, Siegesmund S (2001) Deterioration characteristics of marbles from the Marmorpalais Potsdam (Germany): a compilation. Z dt Geol Ges 152:637-664

Sage JD (1988) Thermal microfracturing of marble. In: Marinos PG, Koukis GC (eds) Engineering geology of ancient works, monuments and historical sites, Rotterdam, pp 1013-1018

Scheffzuek C, Siegesmund, S Koch A (2004) Strain investigations on calcite marbles using neutron time-of-flight diffraction. In: Siegesmund S, Viles H, Weiss T (eds) Stone decay hazards. Environ Geol 46:468-476

Scheffzük C, Siegesmund S, Nikolayev DI, Hoffmann A (2007) Texture, spatial and orientation dependence of internal strains in marble: a key to understanding the bowing of marble panels? In: Přikryl R, Smith BJ (eds) Building stone decay: from diagnosis to conservation, special publications 271. Geological Society, London, pp 237-249

Schouenborg B, Grelk B, Brundin JA, Alnaes L (2000). Buktningsprovning av marmor för fasadbeklädning. NORDTEST-projekt 1443-99: SP Rapport 2000 28, pp 1-31

Siegesmund S, Weiß T, Vollbrecht A, Ullemeyer K (1999) Marble as a natural building stone: rock fabrics, physical and mechanical properties. In: Siegesmund S, Snethlage R, Vollbrecht A, Weiss T (eds) Marmor-Konservierung. Z dt geol Ges 150:237-258

Siegesmund S, Ullemeyer K, Weiss T, Tschegg EK (2000) Physical weathering of marbles caused by anisotropic thermal expansion. Int J Earth Sci 89:170-182

Siegesmund S, Koch A, Ruedrich J (2007) Ursachen mangelnder Formbeständigkeit von Fassadenplatten: Fallstudie Universitätsbibliothek der Universität Göttingen. In: Siegesmund S, Ehling A (eds) Rohstoff Naturstein Teil 1. Z dt Ges Geowiss 158:630648

Thomasen SE, Ewart CS (1984) Durability of thin-set marble. In: Proceedings of the third international conference on durability of building materials and components, pp 313-323

Tschegg EK, Widhalm C, Eppensteiner W (1999) Ursachen mangelnder Formbeständigkeit von Marmorplatten. In: Siegesmund S, Snethlage R, Vollbrecht A, Weiss T (eds) Marmor-Konservierung. Z dt geol Ges, 150, Stuttgart, pp 283-297

Weiss T, Leiss B, Oppermann H, Siegesmund S (1999) Microfabric of fresh and weathered marbles: Implications and consequences for the reconstruction of the Marmorpalais Potsdam. In: Siegesmund S, Snethlage R, Vollbrecht A, Weiss T (eds) MarmorKonservierung. Z dt geol Ges 150:313-332

Weiss T, Rasolofosaon PNJ, Siegesmund S (2001) Thermal microcracking in Carrara marble. Z dt Geol Ges 152:621-636

Weiss T, Rasolofosaon PNJ, Siegesmund S (2002a) Ultrasonic wave velocities as a diagnostic tool for the quality assessment of marble. In: Siegesmund S, Weiss T, Vollbrecht A (eds) Natural stones, weathering phenomena, conservation strategies and case studies, special publications 205. Geological Society, London, pp 149-164

Weiss T, Siegesmund S, Fuller ER (2002b) Thermal stresses and microcracking in calcite and dolomite marbles via finite element modelling). In: Siegesmund S, Weiss T, Vollbrecht A (eds) Natural stones, weathering phenomena, conservation strategies and case studies, special publications 205. Geological Society, London, pp 89-102

Weiss T, Siegesmund S, Fuller E (2003) Thermal degradation of marbles: Indications from finite element modelling. Build Environ 38:1251-1260

Weiss T, Saylor D, Fuller E, Siegesmund S (2004) Prediction of the degradation behaviour of calcareous rocks via finite-element 
modelling. In: Proceedings of the 10th international congress on deterioration and conservation of atone, Stockholm, pp 163-170 Winkler EM (1994) Stone in Architecture. New York

Winkler EM (1996) Technical note: properties of marble as building veneer. Int J Rock Mech 33:215-218
Zeisig A, Siegesmund S, Weiss T (2002) Thermal expansion and its control on the durability of marbles. In: Siegesmund S, Weiss T, Vollbrecht A (eds) Natural stones, weathering phenomena, conservation strategies and case studies, special publications 205. Geological Society, London, pp 65-80 